\title{
Hormonal Control of the Phase Polyphenism of the Desert Locust: A Review of Current Understanding
}

\author{
Amer I. Tawfik*
}

Department of Zoology/Entomology, Faculty of Science, Assiut University, Assiut 71516, Egypt

\begin{abstract}
Locusts show density-dependent continuous phase polyphenism; they appear in two forms or phases, gregarious and solitary, and there is a continuous range of intermediates between the extreme phases. The endocrine control of phase polyphenism has been the most intensively studied in desert locusts, Schistocerca gregaria, Indeed, results of investigations over the past 15 years, provide some of the most detailed information on the endocrine mechanisms that potentially regulate desert locust phase polyphenism. In addition, recent studies on the juvenile hormone titres, ecdysteroid titres, the discovery of $\left[\mathrm{His}^{7}\right]$-corazonin as dark-colour-inducing neuropeptide (DCIN) and the involvement of serotonin pulse in the metathoracic ganglion that triggers behavioural gregarization in the desert locust have yielded not only a good progress in our understanding the endocrine control of phase polyphenism but also unexpected results which indicate that the endocrine control of desert locust phase polyphenism is more complex than envisioned by the classical model. This review gives an overview of the progress made to date in elucidating the hormonal control of the desert locust phase polyphenism. Moreover, this review will summarize these findings and present some questions that still need to be answered.
\end{abstract}

Keywords: Locusts, Schistocerca gregaria, phase polyphenism, juvenile hormone (JH), ecdysteroids, neuropeptide, [His ${ }^{7}$ corazonin, neurotransmitters and neuromodulators, central nervous system (CNS), aggregation pheromone.

\section{INTRODUCTION}

The term phase was first formulated by Uvarov [1] to clarify the taxonomic status of different morphological forms of Locusta migratoria exhibiting typical behaviour. This species, and in fact all locust species, respond to population density in a graded manner. In his original publication, Uvarov chose to describe two extreme phases: 'gregaria' common crowded and swarming population, or 'solitaria' existing as isolated and relatively sedentary individuals. His original phase designation for Locusta migratoria was later expanded by others to all locust species and also to many other insect species [2, 3].

No other pest has for the past four millenia caused such dramatic damage as plagues of locusts. Locusts are perhaps the best known and oldest recorded insect pests. Their voracious appetites, phenomenal migration, and wide geographic distribution have given them legendary status, and despite huge efforts to control them, they remain capable of developing into massive plagues that cause billion of dollars worth of damage to crops. Among the locusts, two species stand out because of their historic and economic importance: namely, the migratory locust, Locusta migratoria, and the desert locust, Schistocerca gregaria. This importance has generated an enormous volume of research, both in the field and in the laboratory, and of the applied and basic kind. Given the economic importance of locusts and grasshoppers, it is not surprising that most of the early studies on locusts

*Address correspondence to this author at the Department of Zoology/ Entomology, Faculty of Science, Assiut University, Assiut 71516, Egypt; Fax:+2-088-2312564; E-mail: Tawfik1@yahoo.com focused on the extrinsic factors that affect phase polyphen ism [2]. Recently, the emphasis has shifted toward the intrinsic factors, especially the endocrine axes, that regulate phase polyphenism [4-7]. Many workers in the field of phase polyphenism have proposed that differences in morphology, colour, behaviour and so forth are manifestations of profound physiological differences between locusts of the two extreme phases. Moreover, it has been specifically suggested that humorally acting factors are responsible for the differential expression of phase characters in gregarious and solitarious locusts.

The desert locust, Schistocerca gregaria is the most devastating of the locust species, and is an important agricultural pest in a vast area of the old world stretching from Mauritania in the west to India in the east, and from Turkey to as far south as Tanzania. It has an invasion area of 29 million $\mathrm{Km}^{2}$, affecting some 58 countries. During plagues, the desert locust has the potential to damage the livelihood of a $10^{\text {th }}$ of the world's population. The 1985-89 (or 1986-89) dramatic plague of the desert locust, S. gregaria [8-10] rekindled interest in locust research. Although this plague declined abruptly in 1989, more recent smaller outbreaks of the desert locust occurred again $[11,12]$ and the locust menace is far from passed. On the other hand, it is not surprising, therefore, that the literature on the locust has increased markedly in the past few years, and many research articles have been devoted to various aspects of locust phases and phase transformation. The present article is an update review focuses on the endocrine control of the desert locust phase polyphensim. This review provides some of the most detailed information on the endocrine mechanisms that potentially regulate desert locust phase polyphenism. This may provide important clues 
to better understand of the hormonal control in the process. This review also, points out gaps in our knowledge and unresolved questions.

\section{Desert Locust Phase Polyphenism}

In order to make the term 'polymorphism' more useful and precise, there is now a tendency to restrict it to genetic polymorphism. Since this would leave nongenetic variation of the phenotype without a designation, the term 'polyphenism' is proposed for it. Polyphenism is the phenomenon where two or more distinct phenotypes are produced by the same genotype. Therefore, most of the relevant recent literature uses the term 'polyphenism' that gradually replaces the older term 'polymorphism'.

\subsection{Phase Characteristics}

Any characteristic which show density-dependent changes in locusts is considered to be a 'phase characteristic'. Such phase characteristics, reflecting differences between gregarious and solitary locusts, are found (and obviously often intermingled) in morphology, colour, anatomy, reproduction, development, physiology, biochemistry, molecular biology, cytology, behaviour and oecology. There are so many phase characteristics that they cannot be fully surveyed in the present review. Only major or recently discovered ones will be discussed. The phase status of the desert locust, S. gregaria has commonly been characterised on the basis of morphometrics [13-18], colour [15, 16, 19, 20], behaviour [21-28], reproductive characteristics such as the number of ovarioles, eggs per egg-pod and pods per female $[16,29]$ and endocrine balance [4-7].

Solitarious desert locusts are non-communal. The nymphal stages are often characterised by a green or straw colour and the adults are greyish brown. Typical adult males and females have $\mathrm{F} / \mathrm{C}$ ratios (hind femur length to head capsule width) $>3.75$ and $>3.85$, respectively $[14,30]$, while their $\mathrm{E} / \mathrm{F}$ ratios (length of fore-wing to hind-femur length) are $<2.03$ in males and $<2.08$ in females. In the gregarious phase, nymphs aggregate as bands of hoppers and mature adults aggregate in swarms. Nymphs have a striking black pattern on yellow background; adults are pinkish when immature and bright yellow when mature. F/C ratios are $<3.15$ for both males and females, and $\mathrm{E} / \mathrm{F}$ ratios are $>2.23$ and $>2.27$ for males and females, respectively [14, 30].

\subsection{Sensillar Polyphenism}

The acridoidea as a group are characterized by the possession of many contact chemosensory sensilla. These occur both as a sparse scattering over the entire surface of the insect, but also as well-defined sensory fields often containing hundreds of sensilla. The principal fields are located on the maxillary and labial palps, the inner surface of the labrum and the antennae [31-35].

In various antennectomy experiments, the antennal olfactory receptor neurons of the desert locust have been implicated as the site of detection of gregarization pheromones. Mordue [36] has demonstrated that removal of the antennae from crowded S. gregaria in the third instars results in fifth instar with the green colour typical of the solitary phase, whereas removal of tarsae or injury to other body parts does not elicit such an effect. Thus, removal of the antennae from crowded insects may stimulate the solitary condition of the locusts [36]. The detection sites of maturation-accelerating pheromones of S. gregaria has been shown by Lohr [37] to be the antennae since removal of the antennae abolishes the vibration response, which consists of antennal waving and lateral movements of the hind legs caused when mature adults or their extracts are held in front of immature locusts [38]. Removal of the palps from immature males does not prevent the vibration response if the antennae are left intact. Moreover, Saini et al. [39] have demonstrated that gravid $S$. gregaria are attracted to and preferentially oviposit in sand treated with volatile compounds from the froth of egg pods. The locusts probe the sand with their antennae before ovipositing.

By scanning and transmission electron microscopy, Ochieng et al. [34] investigated the fine structure and distribution of various types of antennal sensilla in three nymphal stages and in adults of both solitary-reared (solitary) and crowd-reared (gregarious) phases of the desert locust, $S$. gregaria. They identified four types of sensilla: sensilla basiconica, s. trichodea, s. coeloconica and s. chaetica. Starting from the same numbers at the $1^{\text {st }}$ instar, the chemoreceptor sensilla increase more in the solitary phase than in the gregarious phase as the locusts approach adult-hood, whereas the taste/mechanoreception system does not change. The clearest trend between the different phases is observed in the $5^{\text {th }}$ instar and adults where more olfactory sensilla are present in the solitary phase. A reversal of the general pattern of higher sensillum numbers in solitary individuals is found in the $3^{\text {rd }}$ instars. Differences in the numbers of sensilla on the antennae have been also shown between solitary and gregarious phases in other species of Acrididae; Aiolopus thalassinus [40] and S. americana [41].

In accordance with the results by Ochieng et al. [34] in $S$. gregaria, Tawfik and Awad [35] showed that, the numbers of olfactory sensilla differ between solitary and gregarious desert locusts with solitary locusts having a higher number than gregarious individuals. Furthermore, there were significant shifts in the sensillar numbers from solitary to gregarious phase or from gregarious to solitary phase under gregarization or solitarization, respectively. Phase-dependent differences in the behaviour of solitary and gregarious locusts may thus be a result of phase-dependent olfactory integration; gregarious locusts interact socially and are more active compared to isolated solitary locusts which are repelled by crowded locusts and show behavioural responses more consistent with a cryptic lifestyle [26]. As solitary locusts lead to much more dispersed life than gregarious individuals, the need for a higher olfactory sensitivity to detect conspecific-produced odours can be envisaged. The lack of a difference in sensitivity between single receptor neurons of the two phases [42, 43] does, however, not rule out an overall higher sensitivity in the solitary phase as this phase possesses a significantly higher number of sensilla. The higher sensitivity of the solitary phase observed both in electroantennographic and behavioural studies must thus be attributed to a higher number of detecting units $[34,44]$ or, for the behavioural, a central nervous amplification. 
Rearing the insects on plain artificial diet produced much greater changes in the numbers of sensilla on the antennae of S. americana than feeding on different plants with or without additional odours [41]. Rogers and Simpson [45] obtained similar results rearing L. migratoria on wheat and artificial diet. They found that the odour of wheat was sufficient to restore the numbers of olfactory sensilla on the antennae of artificial-diet-fed L. migratoria to the level present in wheatfed insects. Chapman and Lee [41] also found differences in the numbers of olfactory sensilla on the antennae of S. americana that were fed wheat, but exposed to additional different odours. Wheat odour also induced an increase in numbers of trichoid sensilla on the antennae of L. migratoria and a mixture of plant odours had a similar effect on lettuce-fed $S$. americana [46]. The extend to which such differences might occur in the field is unknown, but Chapman and Lee [41] found, in laboratory, that feeding on a single plant species, as opposed to a mixture of species, resulted in an increase in numbers of coeloconic sensilla and a decrease in numbers of trichoid sensilla. It is known that olfactory experience may produce changes in the central nervous system. Technau [47] showed that Drosophila melanogaster deprived of olfactory input as adults had fewer axons in the mushroom bodies. However, this must occur independently of the sensory receptors since these are fully developed at the time of adult emergence. Olfactory experience is also known to affect cell numbers in the olfactory bulb of rats. For example, Rosselli-Austin and Williams [48] found more cells in the mitral and granule cell layers when young rats were exposed to a variety of odours compared with sibling reared in an environment without added odours. These results suggest some direct effect of odour in the numbers of olfactory sensilla.

On the other hand, the existence of aggregation pheromones in the air surrounding S. gregaria and their faeces has been shown by behavioural experiments (see Section 1.3). Aggregation behaviour in the gregarious desert locust, $S$. gregaria is mediated by a complex pheromone system in the volatile emission of the different locust stages, sex and their faeces [for review see 49]. Results by Tawfik and Awad [35] strongly indicated a direct effect of rearing conditions on the development and numbers of olfactory sensilla of $S$. gregaria. Therefore, from the foregoing information one could expect that other effects of the pheromonal systems of gregarious phase of the desert locust may be even more subtle and difficult to detect; for example pheromones could play a role on phenotypic plasticity of the olfactory antennal sensilla. This could be supported by the results of Schafer and Sanchez [50] that in Periplaneta americana a large increase in the number of sensilla responsive to the female pheromone occurs at the moult from final instar nymph to adult male. In addition, there were significantly more chaetica sensilla in the solitary than in gregarious nymphs of S. gregaria but not in adults [34]. This could be due to the differences in the pheromonal responses to the nymphal and adult pheromonal systems.

The chemical cues have been shown to be detected by antennal olfactory receptor neurons (RNs). In antennctomy studies [36, 51], it has been shown that group-reared locusts with their antennae removed lose their gregarization behaviour and develop solitary-phase characteristics even when kept in the company of other locusts, and with visual and tactile stimuli unaffected. A change from the gregarious to the solitarious colour can be induced in gregarious nymphs of $S$. gregaria by isolation [52,53] or by interference with the endocrine system. It is well established that the corpora allata (CA) are closely involved in the formation of the green solitarious colour (see Section 2.3). On the other hand, it is of considerable interest that the removal of the antennae in nymphs of $S$. gregaria brings about colour changes in the cuticle and haemolymph which are remarkably similar to those which follow solitarization or implantation of CA [36]. Moreover, exogenous JH definitely has an effect in the number of the antennal sensilla differentiated from nymphal to adult type in cockroaches [50, 54-56]. For example, in Blatella germanica all types of sensilla increase in number at the final moult and this increase is prevented if $\mathrm{JH}$ is injected into the nymphs [56]. Locust density is the primary extrinsic factor that affects phase transformation and pheromone production [for review see 7,49 ]. On the other hand, recent studies showed phase differences in the endocrine factors between the two phases of $S$. gregaria (see Sections 2-5). Thus it seems that the phase differences in the number of olfactory sensilla could be correlated with the differences in the endogenous (endocrine) factors between the two phases of the desert locust, S. gregaria (see Section 4.2).

Cuticular structures can only be changed at ecdysis, but it is unknown how sensory experience can influence the number of sensilla in subsequent instar. It is unknown whether the observed decreases [gregarization of solitary locusts, 35] were due to the disappearance of already existing sensilla, the failure to produce new sensilla or combination of both. Under normal circumstances, new sensilla are added to the population of sensory field at each moult with existing sensilla being maintained from one instar to the next [57]. Rogers and Simpson [45] suggested that the increases are a result of direct neural stimulation of the sensilla causing the epidermis to differentiate additional sensilla. There seems to be no other plausible explanation, but the differential effects along the antenna require some further consideration. It is possible that the sensilla are physiologically differentiated along the length of the antenna so any olfactory effect might be a result of the differential distribution of receptor-cell types. Whilst there is a sizeable literature on the development of new sensilla, this seems exclusively dedicated to sensillogenesis in embryos, on new cercal annuli, or that occurring during pupation when there is a complete remodeling of the entire cuticle [58-62] but very little is known of the genesis of new sensilla in an existing field.

The locust olfactory system offers the opportunity to study both development and plasticity in a sensory system. The study by Tawfik and Awad [35] showed that extensive changes occur on the antennal sensilla of the desert locust during phase shifts. But, are these changes also paralleled by changes in the functional characteristics of antennal receptor neurons? Are the olfactory centers of the central nervous system affected to increase sensitivity further in solitary individuals? These are questions that need to be answered for us to gain a more complete knowledge of olfactory structure and function in the desert locust. 


\subsection{Pheromones}

Analyses of the volatile emission from live fifth-instar $S$. gregaria led to the identification of $\mathrm{C}_{6}$ and $\mathrm{C}_{8}-\mathrm{C}_{10}$ straight chain aldehydes and carboxylic fatty acids, together with smaller amounts of phenol, guaiacol and indole, as the major electrophysiologically active constituents [63]. The benzene compounds are also the major volatile constituents of nymphal and fledging faeces [63]. The second- to fifth-instar nymphs share a common pheromone that is produced by both sexes [64-66]. In laboratory assays, synthetic blends of the eight aliphatic compounds and the two phenolic compounds promoted nymphal aggregation to the same degree as the natural volatiles from live nymphs. First-instar gregarious nymphs appear to rely on a different set of signals for social cohesion [for review see 49].

On the other hand, newly fledged adults do not emit behaviourally or analytically detectable amounts of the adult pheromone [67-69]. They are also indifferent to the nymphal pheromone. However, they aggregate strongly in response to volatiles of their own faeces and those of nymphs, which comprise phenol, guaiacol and indol [66]. Field observations indicate a close association between fledgings and hoppers and associated with them, large amounts of faecal droppings [66, 70]. Thus nymphal and fledging volatiles may act as a transient aggregation signal for the young adults until they start to produce the adult pheromone [66].

Analyses of airborne volatiles of older adults (from about 10 to 12 days after fledging) showed in males the presence of six electrophysiologically active benzene compounds, anisole, veratrole, benzaldehyde, guaiacol, phenylacetonitrile (PAN) and phenol $[67,68]$. PAN was the dominant component, accounting about $80 \%$ of emissions of the older and mature males. While phenols are products of locust gut bacterial activity [71], PAN and benzaldehyde are biosynthetic products of phenylalanine produced in the epidermal cells of wings and legs of the desert locust [72]. Females produced only traces of guaiacol and phenol, consistent with behavioural assays that showed that females do not elicit significant clumping responses from conspecific adults of either sex $[65,67]$. Of the six compounds, anisole and veratrole did not elicit significant aggregation. Of the rest, PAN was the most active. Interestingly, single-cell recordings from antennal olfactory receptor neurons and antennal lobe interneurons showed the presence of groups of neurons that were specifically excited by the six compounds, and others that were identified as blend specialists responding to specific mixtures of the pheromone components [42, 73].

On the other hand, in a recent study with mature crowdreared S. gregaria, Seidelmann and Ferenz [74] observed a different effect of PAN. In mating experiments, crowdreared males were found to make pairing attempts with or to jump on solitary-reared males, but not with crowd-reared males nor with crowd-reared male-female mating pairs. When solitary-reared males or crowd-reared females were treated with PAN, no pairing attempts by gregarious males were observed. The authors concluded that PAN acts as a repellent in the desert locust and function solely as a courtship-inhibiting pheromone [74, 75]. In a follow-up study, Seidelmann et al. [76] documented the responses of different stages (fifth-instar nymphs, young and mature male and fe- male adults) of crowd-reared desert locust individuals released downstream in a Y-shaped olfactometer with an upstream choice of clean air in one arm and another treated with PAN with and without other constituents of the adult male pheromone blend. Within the observation time (180 s), only a small proportion of the insects (e.g. between $13.2 \%$ and $27.7 \%$ of the released mature males at different PAN doses) moved up the pheromone plume to the arm of the olfactometer that functioned as the pheromone source. A large proportion of the insects was located either close to the release point or further downstream near the exit of the olfactometer. The authors interpreted this distribution pattern as confirming the repellent action of PAN on the insect and downstream movement toward the exit as 'escape reaction'. Interestingly, Rono et al. [77] studied the responses of crowd-reared, mature male $S$. gregaria to increasing doses of PAN in two types of arena. They reported two releaser functions of the adult male-released pheromone that are dependent on different sensory thresholds: arrestment and cohesion at lower relative concentrations and male-male homosexual avoidance at higher relative concentrations. It seems that, gregarious-phase desert locusts demonstrate a relatively complex social structure almost comparable to those of social insects, and the different releaser and primer functions of the gregarious male-produced pheromone demonstrate an interesting case of evolutionary response of the species to the different demands of a cohesive population.

Two studies from different laboratories on the maturation-accelerating effects of gregarious mature male $S$. gregaria and their pheromonal candidates have been described. In both studies, the maturation rates of immature males in contact with mature males or their pentane or hexan extracts were significantly faster than those of unexposed immature males [78, 79]. Exposure of up to 8 days was necessary for maturation effects to be observed [78]. In females, maturation acceleration was reflected in earlier increases in haemolymph vitellogenin titres [80]. Insects exposed to the full blend (anisole, benzaldehyde, veratrole, 4-vinylveratrole and PAN) and one without veratrole (four components) mated at approximately the same time as those exposed to volatiles from live mature males [78, 81]. However, Assad et al. [82] investigated the nature of the maturation-retarding signal associated with the desert locust using two-story aluminum cages, which exposed recipient insects in the bottom chamber to test volatiles from the upper chamber. The effects of the presence of male or female fifth-instar $S$. gregaria on the maturation of immature adults were compared with exposure of the latter to volatiles from fifth instars, their faeces and synthetic blends of the nymphal aggregation pheromone. The authors showed that maturationretarding effects of nymphs on groups of immature adults are attributable wholly to their aggregation pheromone. None of the different groups of constituents (aldehyds, acids or benzene compounds) on their own had significant effects on maturation. Therefore, the nymphal pheromone plays a dual role, as the nymphal aggregant (a releaser effect) and as an adult maturation retardant (a primer effect).

The group-oviposition inducing pheromonal effect was related to the froth (or foam) of the egg pods and sand contaminated with such froth [39]. These results differ from those of Norris [83] who did not find attraction to sand con- 
taminated with froth and faeces in S. gregaria, but agree with the results of lauga and Hatte $[84,85]$ who reported that sand used for repeated oviposition attracts both sexes and it is a preferred medium for oviposition in L. migratoria. Recent work identified veratrole and acetophenone as two major behaviourally active component of the group-oviposition pheromone in S. gregaria [86]. The possibility of additional constituents specifically associated with sand following oviposition by S. gregaria was explored by Torto et al. [87]. Trapped volatiles from moistened contaminated sand enhanced oviposition by $S$. gregaria. Analyses of the volatile collection revealed the presence of three behaviourally active unsaturated ketones, (Z)-6-octen-2-one, (E,E)-3,5-octadien2-one and its $(E, Z)$ isomer [87].

\section{The Role of Corpora Allata and Juvenile Hormone}

\subsection{Corpus Allatum (CA) and its Ultrastructure}

Highnam and Haskell [88] studied the corpus allatum (CA) volume and its increase during the sexual maturation of adult female locusts (L. migratoria and $S$. gregaria) under various experimental conditions. The authors found that the maximum volume of the CA, as related to oocyte length, was quite similar in isolated flown and unflown and in crowded flown females of L. migratoria kept without males. However, the major increase in gland volume occurred at a smaller oocyte length in the crowded flown females than in the isolated (flown or unflown) ones. The steepest increase in this species was observed in unflown crowded female kept without males, and maximum gland volumes in this group greatly exceeded those in the other three groups. The results obtained by Highnam and Haskell [88] in S. gregaria were somewhat different. In adult females kept without males, the maximum volumes of the CA were quite similar in unflown isolated, flown isolated and unflown crowded locusts and a little smaller in flown crowded ones, but the increase in gland volume was steeper in the crowded than in isolated females. The highest gland volumes and steepest increase were found in crowded females kept with mature males producing maturation-accelerating pheromone (see Section 1.3); such females also showed the shortest period of sexual maturation. Regardless of density and flight, maximum volume of the CA in adult $S$. gregaria females coincided with 4-6 mm length of the proximal oocytes.

Measuring CA volume in the penultimate and last-instar female hoppers and in adult females of S. gregaria, Injeyan and Tobe [29] reported consistently larger volumes in isolated than in crowded locusts. These findings somewhat differ from those of Highnam and Haskell [88], but direct comparison may not justified because the isolated locusts of Injeyan and Tobe [29] were reared for two more generations under strict isolation, whereas, Highnam and Haskell [88] separated their locusts from a crowded stock only at the moult to adult. Also, Dale and Tobe [89] found larger CA volumes in isolated than in crowded adults females of $L$. migratoria during the first 8 days after fledging. On the other hand, Tawfik [90] and Tawfik et al. [91] found that the CA volume of both solitarious and gregarious females, S. gregaria varied cyclically in relation to growth of the oocytes. During the first gonadotropic cycle, the maximum length of the basal oocyte peaked just after the first peak of the CA volume (about 2days later) in both phases. Interestingly, during the second gonadotropic cycle, the CA volume of gregarious females coincided with the maximum length of the basal oocyte. In contrast, in solitarious females the second peak of the CA volume appeared just before the maximal length of the basal oocyte during the second gonadotropic cycle. Close inspection of Tawfik [90] and Tawfik et al. [91] data showed that the CA volumes of solitarious females of $S$. gregaria are larger than those of gregarious counterparts that is probably true only for a brief period (day 4) during the first gonadotropic cycle. At all other times in this cycle, they are similar or just offset because of the apparently faster development of the CA of gregarious females. However, following the peak CA volumes in the second cycle (after day 20), that of solitarious females was indeed larger.

Moreover, Joly and Joly [92] and Joly [93] observed that implantation of extra CA into crowded L. migratoria hoppers results in a decrease of the $\mathrm{E} / \mathrm{F}$ ratio associated with the solitarious phase. On the other hand, allatectomy of the gregarious adult males, $S$. gregaria resulted in complete loss of the yellow colour associated with gregarious insects, an effect that was reversed by re-implantation of CA or administration of JH [37, 94]. In addition, Tawfik et al. [91] found that, in adult male $S$. gregaria, CA volumes in the two phases show contrasting changes with time, although they start from comparable values. The increase in the CA volume of gregarious males during the first two weeks followed by its decrease. Similar observation was previously reported by Odhiambo [95]. Interestingly, Tawfik et al. [91] showed that, the occurrence of maximal CA size (days 7-16) correlates with the onset of emission of the aggregation-maturation pheromone (see Section 1.3).

Electron microscopy of the CA in the solitary and gregarious adult male, $S$. gregaria in relation to pheromone production was examined in laboratory-bred desert locust [96]. The ultrastructure of the CA showed differences between the solitary and gregarious insects in particular regarding the smooth endoplasmic reticulum (SER), ribosomes and mitochondria. The ultrastructural study by Tawfik and Mohammed [96] revealed that at the time of maximal pheromone production (20-day-old) the CA cells of gregarious adult male, S. gregaria contain small number of mitochondria, SER and ribosomes. In addition, the nucleoli were mainly in the form of hollow spheres. Whereas, before and after the maximal pheromone production the CA cells had well developed SER, numerous mitochondria and abundant ribosomes. Moreover, Odhiambo [95] reported more SER and mitochondria of more complex shapes in CA of adult male, $S$. gregaria developing toward sexual maturity than in those just after adult emergence.

The ultrastructural study by Tawfik [90] revealed that, the CA cells of gregarious adult female, $S$. gregaria are much better developed compared to the solitary individuals. Also, they showed an earlier appearance and greater abundance of vesicles of endoplasmic reticulum and numerous mitochondria in gregarious females compared to solitary locusts. Moreover, Tawfik [90] reported that, the CA cells of gregarious adult females reach their activity earlier than those of solitary counterparts. This correlate well with the results by Norris [97] and Papillon [98] that, the time elaps- 
ing between fledging and first oviposition is shorter in crowded than in isolated adults, S. gregaria. Papillon et al. [99] also reported the earlier appearance and greater abundance of vesicles of endoplasmic reticulum in sexually mature $S$. gregaria compared to immature locusts.

\subsection{Biosynthesis and Titre of Juvenile Hormone (JH)}

Injeyan and Tobe [100] reported that JH biosynthetic activity of the CA, assessed by radiochemical assay in vitro, was higher in isolated than in crowded penultimate and lastinstar female hoppers of $S$. gregaria. In the same study, the activity of the CA was found to be slightly lower in crowded than in isolated adult females, but major differences were temporal; the isolated locusts exhibited relatively higher rates of $\mathrm{JH}$ synthesis earlier in the first gonadotropic cycle. This earlier activity of the CA correlated well with a shorter period from fledging to first appearance of the vitellogenic oocytes in isolated females. However, in spite of the initially higher gland activity, vitellogenic oocyte development was slower in the isolated females, and eventually the crowded females completed the first gonadotropic cycle earlier than the isolated ones. JH biosynthetic activity of the CA was similar in crowded and isolated adult female, L. migratoria within the first 5-6 days after fledging, but on day 8 gland activity was much higher in isolated locusts [89]. As no data were presented for older females, the difference found in the 8-day-old females may be related to the shorter maturation time of isolated Locusta adults.

In previous studies, employing the Galleria bioassay, Joly and Joly [101] and Joly et al. [102] found higher haemolymph $\mathrm{JH}$ titres in isolated than in crowded fourthand fifth-instar hoppers of L. migratoria. These authors have also observed that in isolated young Locusta adults $\mathrm{JH}$ titres increased much more rapidly with age than in crowded ones, but detailed inspection of their data reveals that maximum values were only slightly higher in the isolated locusts. Using the more reliable method of gas chromatography-mass spectrometry (GC-MS), Dale and Tobe [89] found low JH III titres in 1-day-old adult Locusta females and no differences between isolated and crowded locusts at this age. The titres were much higher on day 4, and the increase was approximately twice as great in isolated than in crowded females. Fuzeau-Braesch et al. [103] assessed JH titres in last-instar hoppers and adult of L. migratoria, comparing crowded, isolated green, isolated homochrome (light coloured) and artificially 'solitarized' (by $\mathrm{CO}_{2}$ ) locusts. Except for higher JH III titres in artificially 'solitarized' ( $=\mathrm{CO}_{2}$ treated) locusts, no clear differences were found; thus these authors concluded that their results do not confirm the assumption that isolated locusts have higher JH titres.

On the other hand, Tawfik et al. [91] studied time-course haemolymph $\mathrm{JH}$ titres in solitarious and gregarious adults of S. gregaria, and their relation to pheromone emission, CA volumetric changes and oocyte growth. By GC-MS analyses, Tawfik et al. [91] confirmed that only JH III was detectable in the haemolymph of the desert locust $S$. gregaria. The authors reported that, the $\mathrm{JH}$ titres in the first gonadotropic cycles of both phases correlate well with CA volumes and oocyte development, but not much correlation is found in the second cycle. In addition, they found that, the $\mathrm{JH}$ titres of gregarious females were generally higher than those females at ages studied. The titre pattern, however, were similar: relatively high on day 10 , dropping to low levels between days 20 and 25, before rising again by day 25. This contrast with previous reports of higher $\mathrm{JH}$ titres in solitarious $L$. migratoria than in their gregarious counterparts [89, 102]. This could be, in part, in the fact that the earlier work on $L$. migratoria did not compare JH titres between phases over an extended period. Also, it may be due to phase-related differences in maturation rates in the two species $[4,7]$. On the other hand, Tawfik et al. [91] found that, in the solitarious adult males of $S$. gregaria, the JH titre was very low on day 10 after fledging, but increased gradually and reached a maximal amount on day 30 . Whereas, the $\mathrm{JH}$ titre in gregarious males was low on day 10, elevated on day 15 coinciding with the start of the production of the pheromone, and dropped to a relatively low level on day 20 around the time of maximal pheromone production, then rising again by day 25. However, Tawfik [104] studied the effect of shifting to crowded (gregarization) or solitary (solitarization) conditions on JH titres in laboratory-bred desert locust, S. gregaria. He reported that, the haemolymph $\mathrm{JH}$ titres in adult, $S$. gregaria are significantly shifted from the gregarious to the solitary phase and from the solitary to the gregarious phase under solitarization and gregarization, respectively. The haemolymph $\mathrm{JH}$ titres in adult females, $S$. gregaria by Tawfik [104] confirmed previous results of higher JH titres in gregarious than in their solitarious counterparts [91].

\subsection{Effects of Juvenile Hormone (JH), Anti-JH and $\mathrm{JH}$ - analogs Treatment}

Implantation of extra CA, or administrations of $\mathrm{JH}$ or $\mathrm{JH}-$ analogs (JHAs), to crowded hoppers induce the green solitary colour. This effect was demonstrated in L. migratoria [53, 92, 105-109] and S. gregaria [110, 111]. Even green isolated hoppers became greener after implantation of extra $\mathrm{CA}$ [112], and injection of $\mathrm{JH}$ to isolated non-green (homochrome) hoppers of Locusta also induced a green colour [113]. Recent studies reconfirmed the green colourinducing effect of $\mathrm{JH}$ and $\mathrm{JH}$-analogs (JHAs), even in an albino strain of L. migratoria [114, 115]. Tanaka [115] studied the effect of JH III on albino nymphs of L. migratoria. They showed that the intensity of the green colouration is dependent on the timing of the injection. The sensitivity to $\mathrm{JH}$ tended to increase towards the end of the instar, and a dramatic change in the sensitivity to $\mathrm{JH}$ was found before and after ecdysis: nymphs injected with JH 2 or 3 hours before ecdysis to the fourth instar turned green, whereas those injected $1 \mathrm{~h}$ after ecdysis to the third instar failed to develop green colour. Moreover, employing exactly timed chemical allatectomy by precocene, Pener et al. [116] demonstrated that chemical allatectomy of green isolated hoppers $L$. migratoria leads to the disappearance of green colour. The resulting hoppers colouration was similar to 'homochrome' (non-green) solitary colour and completely different from the gregarious colouration.

The yellowing of crowded adult locusts depends completely on the CA and the $\mathrm{JH}$ they produce. Allatectomy of last-instar hoppers of young adults prevent yellowing, whereas, reimplantation of CA or administration of $\mathrm{JH}$ reduces it in S. gregaria, [37, 94, 95, 117-120]. Allatoectomy of sexually mature yellow adults, $S$. gregaria results in the 
fading of the yellow colour [117]. Moreover, implantation of extra CA into isolated adults does not induce yellowing, whereas transfer of isolated adults into newly formed crowds does, even without implantation of extra CA [121].

In addition, Amerasinghe [120] found that injection of synthetic JH I induced sexual activity in crowded allatectomized males of $S$. gregaria. Five days after the injection, the intensity of mating behaviour of the allatectomized males temporarily approached that of normal (non allatectomized) males. Injection of JH III into crowded allatectomized males induced feeble intensity of mating behaviour; its level was much lower than that induced by JH I. Both JH I and JH III promoted yellowing in crowded allatectomized males, but JH I was more effective than JH III. Pener and Lazarovici [94] also tested the effect of exogenous JH I and JH III on mating behaviour and yellowing of crowded allatectomized males of $S$. gregaria, employing injection or topical application. Injection of either $\mathrm{JH}$ I or JH III induced mild intensity of mating behaviour in crowded allatectomized males, as assessed by percentage of time spent on sexual behaviour, but topical applications were ineffective. Intensity as high as that showed by unoperated or sham operated controls was obtained with a 1:1 mixture of

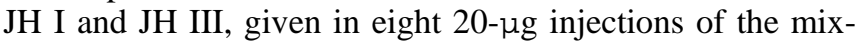
ture at 2-day intervals (cumulative dose $160 \mu \mathrm{g}$ ). In this experiment, the tested males showed mating behaviour for up to 4 weeks (including the first 14 days during which the injections were administered).

On the other hand, Wiesel et al. [122] investigated in the laboratory the effect of JH III and fenoxycarb (JHA), as well as two other JHAs, connoted KA 4580 and BASF 228743, on three phase-related behavioural patterns in S. gregaria and $L$. migratoria. The behavioural patterns studied were (1) 'aggregation' (grouping) of hoppers; (2) marching of hoppers and (3) 'aggression', meaning reaction to confrontation with other individuals of hoppers or of adults. They found that $\mathrm{JH}$ III and JHAs dose-dependently and significantly reduced aggregation of crowded hoppers in both species, suggesting a solitarizing effect. In contrast, marching behaviour, a gregarious characteristic, was stimulated by administration of JHAs; the so intensified marching behaviour surpassed that of the crowded controls. Crowded control locusts showed mostly 'weak' responses in confrontation with fellow locusts, whereas isolated control locusts exhibited mostly 'strong' reaction. After treatment with JHAs, the tested locusts showed an increase of strong reaction and a slight decrease of weak reactions; these responses may be considered as a solitarizing effect. Wiesel et al. [122] found similar trends in both $S$. gregaria and $L$. migratoria, though the later was slightly less responsive than the former. JH III was generally less effective than JHAs.

However, Applebaum et al. [123] studied the effect of a JHA, methoprene, on the nymphal behaviour of S. gregaria and $L$. migratoria by applying topically in acetone $50 \mu \mathrm{g}$ of the substance to newly moulted fourth-instar crowded hoppers. They defined two variables to assess the effect; 'activity level', which is the duration of time spent in movement within a 2-min period, and 'associative index', which reflects the positional relations (grouping) of the hoppers. Five hours after methoprene treatment, the gregarious nymphal behav- iour was shifted towards solitarious behaviour in both species. However, the effect was temporary; $72 \mathrm{~h}$ after treatment, the hoppers of both species exhibited gregarious behaviour. The authors argued that Wiesel et al. [122] did not test long-term effects of the JHAs, and this may explain the different conclusions of the two studies; also, the assay procedures were different, Moreover, it cannot be ruled out that, despite relative persistence of methoprene, its activity was partially or completely lost $72 \mathrm{~h}$ after the treatment. Applebaum et al. [123] also examined the effect of methoprene on nymphal colouration and the $\mathrm{F} / \mathrm{C}$ ratio of the subsequent adults. The colouration of the crowded nymphs was shifted towards green or greenish tints in a portion of the hoppers of both species. The F/C ratio of the adults remained 'gregarious-like' in both species, reconfirming old conclusion that the F/C ratio is not affected by CA/JH [93].

Furthermore, Ignell et al. [124] investigated the effect of $\mathrm{JH}$ on behavioural patterns of adult $S$. gregaria in response to PAN, which is considered to be the most potent adult aggregation pheromone component in this species [49]. They also studied the effect of JH on the responsiveness of olfactory interneurons in the antennal lobe to several substances, considered to be pheromones or pheromone components in adult $S$. gregaria. They showed that the behavioural response to the major and most potent adult aggregation pheromone component, PAN, is age- and JH-dependent. Furthermore, the authors reported that $\mathrm{JH}$ influences the responsiveness of olfactory interneurons in the antennal lobe to aggregation pheromone, whereas the responsiveness of antennal receptor neurons is not changed. Old locusts and locusts injected with $\mathrm{JH}$, in contrast to young locusts and locusts deprived of $\mathrm{JH}$ through allatectomy, do not display any aggregation behaviour, as indicated by long-term behavioural observations.

The effects of three JHAs, fenoxycarb, BASF 228743 and KA 4580, as well as JH III on oocyte maturation in adult females of $S$. gregaria were tested [125]. Treatment of crowded females with JHAs and JH III induced an earlier appearance of vitellogenin in the haemolymph and earlier onset of oocyte growth. JH III exerted the weakest effect. JHAs increased the number of mature eggs in the first gonadotropic cycle; in the case of fenoxycarb and BASF 228743; this number was similar to the number of eggs in isolated controls. However, all JHAs induced oversized oocytes. They found that the first oviposition of crowded controls was observed on day 17 after fledging, whereas that of isolated controls occurred earlier, on day 12. JHAs and JH III administered to the crowded females induced earlier first oviposition, with a period similar or even shorter than of the isolated controls. However, the authors mention that only in a few cases did first oviposition of the isolated control females occurred on day 11/12, and most isolated females retarded oviposition for some time, up to many days. But accelerated oocyte maturation and earlier egg laying is not a solitarious characteristic in $S$. gregaria. In this species, crowding accelerates maturation [for review see 49]. Schneider et al. [125] also reported that JHAs and JH III affected lipid metabolism in S. gregaria females, shifting the fresh weight of the fat body towards lower, solitarious, values and reducing the adipokinetic response observed after $60 \mathrm{~min}$ of flight. The authors interpreted the effects of JHAs and JH III 
on reproduction and lipid metabolism as solitarization of the crowded females.

The role of $\mathrm{JH}$ in the maternal regulation of progeny characteristics was examined in the desert locust, S. gregaria [126]. Female adults of this species are known to produce smaller but more eggs when reared in isolation than those reared in a group. The authors showed that topical application of JHA, fenoxycarb, or implantation of CA, caused crowded S. gregaria females to deposit smaller eggs, but did not have a significant effect on the number of eggs per egg pod except at higher doses of JHA. The production of smaller eggs by treated and untreated crowded females was closely associated with earlier deposition of the egg pods and shorter oviposition intervals. However, they reported that, neither JHA nor CA implantation influenced the progeny characteristics in actively reproducing aged females under crowded conditions, while untreated control females started producing smaller and more eggs upon transfer to isolated conditions. Maeno and Tanaka [126] suggested that JH is not directly involved in the maternal regulation of phasedependent progeny characteristics.

On the other hand, Wedekind-Hirschberger et al. [127] investigated haemolymph polypeptides in laboratory strain and field catches of S. gregaria, revealing that some of the polypeptides are phase-specific. They applied topically a JHA, $150 \mu \mathrm{g}$ of fenoxycarb per locust, to crowded males at day 0 after fledging and found that with sexual maturation ( $\geq$ 15 days after fledging), 9 of 17 gregarious-specific polypeptides were repressed. They also found that two of three solitarious-specific polypeptides were expressed after JHA treatment of crowded males. But the physiological roles of these polypeptides are unknown.

The effects of juvenile hormone treatment on phase changes and pheromone production (as measured by the amounts of PAN released) in the desert locust, $S$. gregaria were studied [128]. Tawfik et al. [128] administered JH III to 3- to 5-day-old last-instar hoppers and, separately, 3- to 5day-old young adults of crowded $S$. gregaria males, by three alternative routes, topical application in acetone, injection in olive oil and exposure to vapour ('fumigation'). The authors recorded the effect of the treatments on the timing and rate of PAN release. Topical application of a single dose of $50 \mu \mathrm{g}$ of JH III to hoppers or young adults was ineffective; the onset of PAN release was similar to that of the controls. Topical application of $50 \mu \mathrm{g}$ of $\mathrm{JH}$ III on each of the days, 3, 4, and 5 after the moult $(3 \times 50=150 \mu \mathrm{g}$ cumulative dose), to lastinstar hoppers induced a large delay in the onset of PAN release, up to 30-35 days in the subsequent adult males, as compared with 10-15 days in the controls. Topical application of $50 \mu \mathrm{g}$ of JH III to young adults, on each of the days, 3 , 4 and 5 after fledging $(3 \times 50=150 \mu$ g cumulative dose), also induced a slight delay, about 5 days, in the release of PAN. Injection of $3 \times 50 \mu \mathrm{g}$ of JH III (cumulative dose) into young adults induced a slight delay, similar to that induced by topical application of the same cumulative dose. Injection of $3 \times 50 \mu \mathrm{g}$ of $\mathrm{JH}$ III into last-instar hoppers resulted in a high proportion of mortality, or morphogenetically disturbed locusts in the sixth stadium. Fumigation of last-instar hoppers, exposed to $400 \mu \mathrm{g}$ of JH III vapour, induced maximum delay; the subsequent adult males started to release PAN as late as 35-40 days after fledging. Moreover, Tawfik et al. [128] noted that in the case of topical application of $3 \times 50$ $\mu \mathrm{g}$ of JH III to the hoppers, as well as in the case of exposure of the hoppers to the vapour of $400 \mu \mathrm{g}$ of JH III, the resulting adults showed a faded yellow colour instead of the bright yellow colour of the controls. The authors also stated that exposure to JH III of fifth-instar crowded hoppers of $S$. gregaria shifted the haemolymph pigment ratio (haemolymph absorbance ratio, 460/680 nm) towards that of the solitarious phase. In contrast, exposure of adults at any age to JH III did not affect significantly the 460/680 ratio.

\subsection{Juvenile Hormone Binding Protein (JHBP) and JH Receptor}

Juvenile hormone binding protein (JHBP) was extracted and purified from the haemolymph of crowd-reared adult desert locust, S. gregaria [129]. The JHBP was purified by polyethylenglycol, filtration through molecular weight cut off filters and chromatography on a HiTrap heparin column. Tawfik et al. [129] found that the haemolymph JHBP of locust has a native molecular weight $\left(\mathrm{M}_{\mathrm{r}}\right)$ of $480 \mathrm{kDa}$ with subunits of $77 \mathrm{kDa}$. The locust JHBP binds JH III with moderate affinity; whereas, competition for binding of JH II and JH I was about 2 and 5 times less, respectively. No sequence information was obtained for the locust JHBP. Moreover, JH binding component from the fat body, ovary and testis of the desert locust, $S$. gregaria was analysed in search for JH receptor [130]. Examination of the ovary, testis and fat body, the target organs of $\mathrm{JH}$ action, revealed only a single binder for JH III and this proved to have a native molecular weight $509 \mathrm{kDa}$, which is composed of seemingly identical subunits of $\mathrm{M}_{\mathrm{r}} 74.9 \mathrm{kDa}$. Also, no sequence information was obtained for the locust cytosolic JHBP. Competitive displacement studied with racemic unlabelled JH homologs (JH I, JH II and $\mathrm{JH}$ III) and $\mathrm{JH}$ analogs (methoprene, fenoxycarb and pyriproxyfen) showed that the cytosolic JHBP preferentially binds JH III over other JHs or JH analogs. This is in accordance with earlier observations that JH III is the only identifiable form of the hormone in Acrididae [89, 91, 131, 132].

\section{The Role of Ecdysteroids}

\subsection{Ecdysteroids in Ovaries and Eggs}

During the formation of insect eggs, ecdysteroid conjugates accumulate in the yolk and are hydrolysed during embryogenesis [for reviews, see 133, 134]. Much of our knowledge of the ovarian and embryonic ecdysteroids comes from studies on the locusts, S. gregaria and L. migratoria, in which more than $95 \%$ of all body ecdysteroids in reproducing females are confined to the ovaries and consist mostly of ecdysone conjugates [135]. Ecdysteroids are produced in the follicle cells [136, 137] and converted to conjugates with polar moieties $[138,139]$. The conjugates are bound to the yolk protein, vitellin, and this binding apparently prevents their leakage into the haemolymph [140]. Newly laid eggs are reported to contain high amounts of conjugated ecdysone and 2-deoxyecdysone, smaller amounts of conjugated 20hydroxyecdysone (20-OH-ecdysone), very small amounts of free ecdysone, 20-OH-ecdysone and 2-deoxyecdysone, and traces of other ecdysteroids [139, 141-143]. 
Our knowledge about the ovarian and embryonic ecdysteroids comes from studies on crowded locusts [135, 139-142, 144-148]. Employing RIA and HPLC, Tawfik et al. [143] were the first authors to investigate and compare, in $S$. gregaria, phase-dependent ecdysteroid content during oocyte development in the ovaries and throughout embryonic development of the subsequent eggs. They found that total ecdysteroid content of the ovaries with developing oocytes (first gonadotropic cycle) was about four times higher in crowded than in isolated females. The difference found in the ovaries also existed during the embryonic development of the eggs; total ecdysteroid content was over six times higher in freshly laid eggs from crowded females than in eggs from isolated females. Tawfik et al. [143] revealed that most ovarian ecdysteroids, over $80 \%$ of the total, were polar conjugates of ecdysone, 20-OH-ecdysone and 2deoxyecdysone. Some of the same ecdysteroids, up to $5 \%$, existed also in a free state. The rest were non-hydrolizable highly polar metabolites. The summation of all these confirmed a four times higher accumulation of total ecdysteoids in crowded than in isolated females' ovary. The only phaserelated difference was found in the proportion of the conjugated ecdysteroids; both crowded and isolated females' ovary contained similar absolute amounts of 20-OH-ecdysone and 2-deoxyecdysone, but conjugated ecdysone was much higher in the ovary of crowded females.

Moreover, Tawfik et al. [143] reported that newly laid eggs contained 14 and 89 ng of 20-OH-ecdysone equivalents per eggs from isolated mothers and in those from crowded mothers, respectively. Total ecdysteroid content of the eggs during the first 6 days of embryonic development did not change much and remained over six times higher in eggs from crowded mothers. Almost all ecdysteroids were maternal conjugates at this age range of the eggs, mostly ecdysone plus a small amount of 20-OH-ecdysone and 2-deoxyecdysone. Small amounts of presumably newly produced 26hydroxyecdysone (26-OH-ecdysone) appeared on day 2 in the eggs of crowded females. The amount of total ecdysteroids increased by about four to five times to maximum values on days $8-10$, reaching $70 \mathrm{ng}$ and nearly $400 \mathrm{ng}$ of 20-OH-ecdysone equivalents per egg in eggs from isolated and in those from crowded mothers, respectively. Then the amount of total ecdysteroids decreased gradually until hatching. These events were quite parallel in eggs from crowded and in those from isolated females, although the ratio of the amount of total ecdysteroids in the eggs from crowded mothers to that in eggs from isolated mothers remained high. Developmental fluctuations and mutual ratios of free ecdysteroids, namely, ecdysone, 20-OH- ecdysone and 26-OH-ecdysone, were also similar. Massive synthesis of conjugates started on days 8-10. Phase-dependent differences in these conjugates were found in 26-OH-ecdysone and 2-deoxyecdy-sone. The conjugates of the former were present from day 2 onwards and constituted up to $6 \%$ of all conjugates in the eggs of crowded females, but in the eggs of isolated females, these conjugates were present only in small amounts in the latest stadia of the embryonic development. The accumulation of 2-deoxyecdysone conjugates in the middle of embryogenesis was about 50 times higher in eggs from crowded than in those from isolated mothers.
Effects of crowding, isolation, and transfer from isolation to crowding on total ecdysteroid content of eggs in $S$. gregaria were investigated [149]. The authors confirmed and extend earlier finding of differences in the content of egg ecdysteroids between gregarious and solitarious desert locusts [143]. The amount of ecdysteroids is considerably higher and undergoes more marked fluctuations during embryogenesis in the eggs of crowd-reared than in those of the solitary-reared females. A brief crowding of solitary-reared females shortly before egg laying, which induces the expression of gregarious characters in the offspring [28], had no effect on the ecdysteroid level in the eggs, nor the foam plugs deposited above the eggs. This result rules out the possibility that the crowding experience of females is transmitted to the offspring by variation in the total amount of ecdysteroids in their eggs. Unfortunately, Hagele et al. [149] investigated only a brief crowding of solitary-reared females at the time of egg laying.

The discovery of significant differences in the content and partly also the composition of ecdysteroids in the eggs of solitary versus the gregarious phases of the desert locust, $S$. gregaria $[143,149]$ is still of a considerable interest. It may be that the ecdysteroids in the egg not only control the deposition of embryonic cuticles [for review see 150], but also play a role in phase dimorphism. On the other hand, the significant differences in the ovarian ecdysteroids between the solitary and gregarious adult female $S$. gregaria could play a role in maturation and reproductive activity. Differences in reproductive activity between the two phases of the desert locust were documented [16, 29, 97, 151, 152].

\subsection{Ecdysteroids in Larvae}

Previous measurements of ecdysteroid were carried out in larvae of $S$. gregaria and L. migratoria reared under crowded conditions [138, 153-156]; only Wilson and Morgan [157] compared solitary and gregarious phases with respect to the ecdysteroid content of the whole bodies of last instar larvae of S. gregaria. They found no differences, and concluded that ecdysteroids play no role in phase dimorphism. The only studies that attempted to compare the composition and titre of ecdysteroids in solitary and gregarious larvae of S. gregaria were conducted by Tawfik et al. [143, 158].

Ecdysteroid content was more than five times higher in hatchlings from eggs laid by crowded mothers than in those from eggs laid by isolated mothers [143]. Moreover, Tawfik et al. [158] showed that the titres of ecdysteroid in the haemolymph of the solitary and gregarious penultimate and last instar larvae of S. gregaria; the longer duration of the moult-inducing surge of ecdysteroid; and the frequently higher proportion of highly polar products distinguish the gregarious from solitary larvae of S. gregaria. On the other hand, it was shown that partial ablation of prothoracic (also called ventral) glands (PGs), after which it was presumed that there would be a reduction in the titre of ecdysteroid, causes the appearance of some gregarious features in solitary hoppers [20], and that injection of phytoecdysteroids into gregarious larvae leads to the appearance of some solitary characters [159]. 
Furthermore, Tawfik et al. [158] have shown that, 20$\mathrm{OH}$-ecdysone is the dominant ecdysteroid in the penultimate and last instar larvae of both sexes, making up 63 to $84 \%$ of the total ecdysteroids. In absolute terms, penultimate instar females contained about $30 \%$ more 20-OH-ecdysone than males, whereas a still lower 20-OH-ecdysone content in the last instar larvae was similar in both sexes. Differences in 20-OH-ecdysone between the solitary and the gregarious phases were significant in both instars and sexes. Differences between the solitary and the gregarious phases were found also in the contents of minor ecdysteroids. The solitary phase differed from the gregarious one by higher representation of ecdysone and the makisterone A-like compound, and lower proportion of highly polar products. Phase divergence was particularly obvious in the penultimate instar, when the solitary larvae contained 3-5x more ecdysone and makisterone A-like component than the gregarious ones. In the last instar, similar phase distinction was pronounced in the males but virtually absent in the females. It is possible that diverse ecdysteroid titres affect morphological, behavioural, and other phase characters only indirectly, via changes in stadium duration. Other effects may be subtle and difficult to detect. For example, ecdysteroids could control the production of aggregation pheromones that were identified from gregarious nymphs of $S$. gregaria [63].

\subsection{Ecdysteroids in Adults}

Studies by Gande et al. [138] and Morgan et al. [153] on ecdysteroids in adults were conducted using extracts of whole bodies of $S$. gregaria reared under crowded conditions. For the adult locusts, however, Carlisle and Ellis [160, 161] reported that the solitary and gregarious phases differ by the size and persistence, and presumably also by the secretory activity of their PGs. Furthermore, the reduction of flight activity in the gregarious adults supplied with implants of these glands [162] was interpreted as evidence for a promotion of the solitary phase characters by ecdysteroids secreted by the implant. More detailed study on the composition and titre of ecdysteroids in the haemolymph and the PGs in solitary and gregarious adults of S. gregaria was carried out by Tawfik et al. [163].

Locusts, in contrast to most other pterygote insects, often retain their PGs for a long time after emergence. The glands were reported to persist permanently in isolated adults of $L$. migratoria and S. gregaria [161], as well as in the crowded L. migratoria kept under a short photoperiod [164]. Even in cases when the glands degenerate, their regression occurs only at the time of sexual maturation [165]. The larval PGs were identified as the only source of ecdysteroids [166], and their potential to secrete ecdysteroids was proven in vitro [167]. It was therefore, justified to assume that the glands of adult locusts also produce ecdysteroids, at least for some period of adult life. However, Tawfik et al. [163] demonstrated that, the glands of male and female, solitary and gregarious adults of $S$. gregaria do not release significant amounts of ecdysteroids at any time, including periods of high titre of ecdysteroid in the haemolymph. A similar result in L. migratoria was obtained by Roussel [168]. So, the PGs of adult locusts are obviously not the source of ecdysteroids circulating in the haemolymph. It should be noted that the content and role of ecdysteroids in the haemolymph of adult locusts are in all likelihood, separate from the functions of the adult PGs. Difference in the persistence of the glands depends on the photoperiod [164] and humidity [165], suggesting an involvement in adaptation to environmental changes. Charlet et al. [169] have suggested that the functions of adult PGs may rest on their peptidergic secretion and be unrelated to ecdysteroids. Recently, Vandermissen et al. [170] detected an 'autocrine factor' in the PGs of last-instar hoppers of L. migratoria and S. gregaria. This factor originates from the PGs themselves and enhances their ecdysteroid production. The report of Vandelmissen et al. [170] rekindled interest in some older publication suggested that the PGs of insects secrete other hormone(s), probably proteins (or peptides), in addition to ecdysteroids.

Sites of ecdysteroid biosynthesis in adults of the desert locust, S. gregaria were investigated by in vitro organ culture techniques [171]. The author showed that the abdominal integument with adhering fat body is a major ecdysteroid source in adults, although other tissues, such as fat body and Malpighian tubules might also be a source of these hormones. In contrast, ovary and testis did not synthesize physiological significant amounts of ecdysteroids in the incubation media. Measurements of total ecdysteroid content in the incubation media indicated that the ecdysteroids increase from day 2 to reach maximum 15 days after adult emergence. In general, the synthetic activity of the integument, fat body and Malpighian tubules was significantly higher in adult females than that of adult males [171]. In addition, Tawfik [171] found that the abdominal integument synthesized and released mainly high polar metabolites, 20,26dihydroxyecdysone, 20-OH-ecdysone and ecdysone in ratio $1: 0.9: 0.4: 0.04$, respectively.

Tawfik et al. [163] studied haemolymph ecdysteroid titres in crowded and isolated adults of $S$. gregaria. They identified the ecdysteroids by RIA, with two different antibodies, both of them most sensitive to ecdysone, but one of them less sensitive to other relevant ecdysteroids. After hydrolysis, the authors found 20-OH-ecdysone, ecdysone, highly polar products and a compound resembling makistron A, like in the hoppers [158]. In the adult males, 20-OH-ecdysone constituted the most abundant ecdysteroid, $73 \%$ of the total in isolated and $94 \%$ in crowded locusts. In both isolated and crowded adult females, about $40 \%-50 \%$ ecdysone and about the same percentage of $20-\mathrm{OH}$-ecdysone were found, constituting together about $86 \%-90 \%$ of haemolymph ecdysteroids. Other ecdysteroids were in smaller amounts and did not exhibit consistent correlation, either with sex or with density.

Moreover, Tawfik et al. [163] reported that haemolymph titres of ecdysteroids in the adults showed a brief peak in isolated and crowded males and in isolated females, on day 4 after fledging, but on day 6 in crowded females. This peak was considerably higher in isolated males than in other adults. After this peak the titres dropped, but a major increase started on days 8-10, coinciding with the onset of vitellogenesis in the females and with the preparatory stage or onset of adult pheromone production by the males, assessed by PAN emission (see Section 1.3). The titres peaked on day 16 in crowded and isolated females and on days 1618 in crowded and isolated males. These peaks reached in 
both sexes about $400 \mathrm{ng}$ of 20-OH-ecdysone equivalent per millilitre haemolymph in the isolated adults, but only about $150 \mathrm{ng} \mathrm{ml}^{-1}$ in crowded adults. The relatively high peak of the isolated males cannot be related to PAN emission, because isolated males do not produce PAN [63]. This fact makes questionable the relation between the much lower in the crowded males and PAN production. This relation is further questionable because in the crowded males, ecdysteroid titre decreased to practically zero by day 40 , but the crowded males still produced a considerable amount of PAN. Also, the somewhat decreasing ecdysteroid titre was still over 100 $\mathrm{ng} \mathrm{ml}^{-1}$ in 40-day-old isolated males, which do not produce PAN. In the females of either phase, haemolymph ecdysteroid titres decreased by day 20 and 24, increased again by day 30 , and then declined by day 40 . Crowded adults began mating on day 14 after fledging, and their first oviposition was observed on day 15-16. Isolated females laid first egg pod on days 18-19 and their second egg pod on days 28-30. This timing of oviposition coincides reasonably well with the main and subsequent peaks of ecdysteroid titres. Control of vitellogenin production by ecdysteroids was suggested for L. migratoria [172]. On the other hand, haemolymph ecdysteroids in males may affect the synthesis of some proteins in the reproductive accessory glands [173] or may have a role in spermatogenesis [174] or both [175].

In addition, Tawfik [176] investigated the effects of shifting to crowded (gregarization) or solitary (solitarization) conditions on the titres of ecdysteroids in the haemolymph and pheromone production in adult $S$. gregaria. The study showed that haemolymph ecdysteroid titres are shifted significantly from the solitary to the gregarious phase or from the gregarious to the solitary phase under crowding or isolating conditions respectively. Existence of such shift indicates that ecdysteroids play a role in adult locusts and that this role is related to phase transformation. The differences in the titres of ecdysteroid between the solitary or solitarized adult and the gregarious or gregarized adult Schistocerca are particularly striking in males, in which the rise in titre begins around day 10, is small and transient in the gregarious or gregarized males, but high and persistent in the solitary or solitarized males. This increase in ecdysteroids is followed closely by increased production of physiologically active volatiles that were identified as a mixture of anisole, benzaldehyde, veratrole, guaiacole, PAN (major product, comprising $75-85 \%$ of the total volatiles) and phenol [67, 163]. This means that the phase characteristics (titre of ecdysteroid in the haemolymph and pheromone production) can be shifted in either direction and the direction of the shift is reversible in the adult stage in response to appropriate changes in density. Differences in titre between the solitary or solitarized males and the gregarious or gregarized males may suggest that ecdysteroids in low concentration stimulate, and in high concentration inhibit, the release of volatiles. Therefore, adult pheromone (PAN) could be regulated by combined differences in the titres of several hormones. The combined effect of an elevated JH titre (see Section 2.3) and a reduced ecdysteroids titre at appropriate age of adult stage may be the key factor that controls PAN production in adult males, $S$. gregaria, rather than variation in the titre of either hormone alone. Ecdysteroids stimulate sex pheromone activity in some insect species $[177,178]$. Furthermore, Adams et al. [179] reported that ovariectomized houseflies do not produce their sex pheromone unless implanted with ovaries (as a source of ecdysteroids) or injected with ecdysteroids.

\section{The Role of Neuropeptide [His ${ }^{7}$-corazonin}

\subsection{The Discovery of $\left[\mathrm{His}^{7}\right]$-corazonin}

Evidence for the existence of a factor promoting the dark colour of gregarious locusts can be found in the older literature. Nickerson [19] is the first who reported that injection of haemolymph from gregarious $S$. gregaria nymphs increased the gregarious black patterns in solitary nymphs. Staal [53] observed that implantation of extra corpora cardiaca (CC) increased the amount of black pattern present with respect to both intensity and extent in L. migratoria nymphs, while extirpation of CC had an opposite effect. Moreover, Girardie and Cazal [180] showed that the brain and CC contain a dark colour-inducing factor originating in the lateral cells of protocerebrum. In spite of such pioneer studies, the nature of these factors and their role in the body-colour polyphenism in locusts remained undefined for a long time.

However, it took almost 40 years before this dark-colourinducing factor from the CC could be purified. Progress became possible due to the discovery of a new albino strain, isolated from a colony of $L$. migratoria originating from the Okinawa island in Japan [114]. Its albinism is caused by a lack in this dark-colour-inducing factor [181, 182]. Darkening could be induced by implantation of CC or injection of methanolic CC extracts from normally pigmented hoppers [183-185]. This bioassay formed the basis for chromatographic purification and elucidation of the factor from CC extracts. It was revealed to be a peptide of 11 amino acids, blocked by pGlu at the $N$-terminal and amidated at the $C$ terminal: pGlu-Thr-Phe-Gln-Tyr-Ser-His-Gly-Trp-Thr-Asn$\mathrm{NH}_{2}$. Initially, it was named 'dark-colour-inducing neurohormone' or 'dark pigmentotropin' [186]. The term $\left[\mathrm{His}^{7}\right]$-corazonin is now more frequently used, because the compound is very similar to the peptide corazonin, which has been identified from the CC of the cockroach Periplaneta americana [187]. This peptide has an Arg instead of the His at position 7.

Corazonin and $\left[\mathrm{His}^{7}\right]$-corazonin are most probably present in the majority of insects. A survey based on 60 insect species indicates that brain-CC complexes taken from 52 species belonging to 10 orders including Othoptera, Dermaptera, Dictyoptera, Isoptera, Homoptera, Hemiptera, Odonata, Hymenoptera, Lepidoptera and Diptera induced dark colour in albino locusts, whereas those from the remaining 8 species belonging to Coleoptera all failed to do so [188]. So far only a few species have been studied to identify the chemical structure of the factors inducing dark colour in albino locusts. The active compound present in the brain-CC complex of a cricket, Gryllus bimaculatus, and a silkworm, Bombyx mori, was found to be [Arg $\left.{ }^{7}\right]$-corazonin [189]. $\left[\mathrm{Arg}^{7}\right]$-corazonin was first isolated from a cockroach, $P$. americana, as the most potent cardiostimulatory peptide [187], and also from another cockroach, Nauphoeta cinerea 
and a sphinx moth, Manduca sexta [190], although its exact function in any of these species has not been fully understood. In G. bimaculatus and B. mori, injections of $\left[\mathrm{Arg}^{7}\right]-$ corazonin modify neither body colour nor development [189]. The corazonin-gene has already been identified in Drosophila melanogaster [191] and in Galleria mellonella [192]. Although some specific actions on visceral muscles of cockroaches [187, 193] and the spinning rate in $B$. mori [194] are known, the full role of these peptides remain largely enigmatic in most of the species investigated to date.

Immunocytochemical techniques have shown that [His ${ }^{7}$ corazonin is present in a limited number of neurosecretory cells in the pars lateralis of the brain of normal (pigmented) L. migratoria and S. gregaria [181], conforming to the results for the neurosecretory factor in L. migratoria [180]. Presumably, the peptide is then transported via the nervi coporis cardiac II to the CC for storage and release into the haemolymph.

\subsection{The Role of $\left[\mathrm{His}^{7}\right]$-corazonin in Phase Transition}

Up to 1999, no major breakthrough was achieved in the purification and characterization of the dark-colour inducing peptide in locusts. Tawfik et al. [186] identified a darkcolour-inducing neuropeptide (dark-pigmentotropin) from the CC of two plague locusts, $S$. gregaria and L. migratoria. The chromatographic isolation of this neuropeptide was monitored by using a bioassay with an albino mutant $L$. migratoria. The neurohormone, consisting of 11 amino acids, is identical to [His ${ }^{7}$ ]-corazonin, previously isolated from CC of another acridid without known function [190]. Fourth instar albino mutant individuals injected by synthetic [ $\mathrm{His}^{7}$ ]corazonin in peanut oil show a slight darkening within 1 day of treatment, but turn completely black after the next moult. The extent of the dark pigmentation is dose-dependent. Injections of $10 \mathrm{pmol}$ or higher concentrations caused most albino nymphs to turn completely black. However, a slight effect was visible even at a dose as low as $10 \mathrm{fmol}$ [186, 195]. By varying not only the dose, but also the time of injection, various types of body colouration can be induced. Uniformly black, brown, fawn, purple and reddish body colours are observed after the injection of [His $\left.{ }^{7}\right]$-corazonin in albino hoppers [196].

Injection of this peptide in field-collected solitarious $L$. migratoria does indeed induce the colouration characteristic for the gregarious hoppers [196]. On the other hand, in $S$. gregaria, injection of corazonin in green isolated-reared hoppers generates the same degree of darkening as in crowdreared hoppers after the following moult [186, 197]. These results confirm the role of [His $\left.{ }^{7}\right]$-corazonin in promoting cuticular melanization and shifting the colour towards that of the gregarious phase. As mentioned above, the green colourinducing effect of $\mathrm{JH}$ has been well documented for $S$. gregaria and L. migratoria (see Section 2.3). Because the green colouration is induced by $\mathrm{JH}$, body-colour polyphenism is apparently controlled by an interaction between [His $\left.{ }^{7}\right]$-corazonin and JH [115, 198]. Moreover, Tawfik et al. [186] reported that finely timed, high doses of the dark-colour-inducing neurohormone (DCIN $=\left[\mathrm{His}^{7}\right]-$ corazonin) of locusts induce gregarious colouration in solitarious nymphs of $S$. gregaria. However, later experiments showed that only the gregarious dark patches, but not the yellow background colour of last-instar gregarious nymphs, are induced by DCIN [198]. This means that in addition to $\mathrm{JH}$ that affects green colouration (see Section 2.3) and DCIN that induces dark colouration and gregarious black patterning $[186,198]$, the discovery of some additional factor(s) involved in the regulation of yellow colouration should be sought.

Recent studies investigated whether this hormone might also be causally related to change in other phase characteristics such as morphometrics and behaviour. Solitary fourthinstar nymphs of $S$. gregaria were injected thrice with 1 nmol [His ${ }^{7}$ ]-corazonin [197]. After moulting to the $5^{\text {th }}$ stadium their behavioural phase state was measured in an arena assay and analyzed using multiple logistic regression analysis. The hormone was found not to induce behavioural phase changes. Upon reaching adulthood, morphometrics (F/C ratio) shifts occurred towards values typical for crowdedreared and regregarized animals. Besides the $\mathrm{F} / \mathrm{C}$ ratio, other morphometrical parameters were also influenced [197]. These results indicated that $\left[\mathrm{His}^{7}\right]$-corazonin is not involved in behavioural gregarization but may participate in mophometrical phase change. Additionally, the effect of (His ${ }^{7}$-corazonin on the abundance of antennal sensilla in the desert locust, $S$. gregaria was investigated by Maeno and Tanaka [199]. Solitarious locusts (reared in isolation) were injected with [ $\left.\mathrm{His}^{7}\right]$-corazonin at the $3^{\text {rd }}$ nymphal instar and the numbers of sensilla on the $2^{\text {nd }}, 8^{\text {th }}$ and $14^{\text {th }}$ antennal segments in the adult stage were compared with those for oilinjected solitarious controls or un-injected gregarious locusts (reared in group). The numbers of sensilla on these antennal segments were all reduced significantly after [His $\left.{ }^{7}\right]$ corazonin injection compared with those of oil-injected controls, but similar to the values for gregarious individuals. Among the four major types of olfactory sensilla, coeloconic, trichoid, basiconic type A and basiconic type B, [His ${ }^{7}$ ]-corazonin injection influenced the abundance of all but the last type. The effect of $\left[\mathrm{His}^{7}\right]$-corazonin injection varied with the time of injection; this 'gregarizing' effect of [His ${ }^{7}$ ]-corazonin was greater when the injection occurred earlier in nymphal development.

As mentioned above, Tawfik et al. [186] succeeded in isolating [His ${ }^{7}$ ]-corazonin (dark-colour-inducing neuropeptide) from the CC of crowd-reared locusts, S. gregaria and $L$. migratoria. On the other hand, Baggerman et al. [182] have found that corazonin is present in the CC of isolated-reared $S$. gregaria. Hence, the effects are not a question of absence or presence of the peptide in the animals of two phases. Because there are also transient forms possible, it is likely to be a matter of the titre of this hormone in the haemolymph being much higher in gregarious locusts than in solitarious ones. Indeed, it can be suggested that corazonin is not released into the haemolymph of solitary locusts. Interestingly, Tanaka et al. [200] showed that [His ${ }^{7}$ ]-corazonin injected into isolated-reared nymphs of $L$. migratoria caused a shift in morphometric ratios ( $\mathrm{F} / \mathrm{C}$ and $\mathrm{E} / \mathrm{F})$ towards values typical for crowd-reared (gregarious) individuals. However, an albino mutant of L. migratoria (Okinawa strain), was capable of undergoing morphometrical phase transition, despite its lack of corazonin [201]. Therefore, the fact that the phase-related morphometric changes can be observed in the albino strain that lacks $\left[\mathrm{His}^{7}\right]$-corazonin suggests that the presence or ab- 
sence of this hormone alone does not explain the whole phenomenon.

\section{The Role of Neurotransmitters and Neuromodulators}

Only octopamine has previously been measured with regard to phase change and the results were unclear. FuzeauBraesch and David [202] reported higher octopamine content in whole heads of isolated than crowded L. migratoria. Moreover, Fuzeau-Braesch et al. [203] assessed octopamine content of heads during the last hopper stadium and in adults at three different ages in L. migatoria. They found higher octopamine in isolated than in crowded females, both in hoppers and in adults, except at ecdysis, when octopamine levels were similarly low in crowded and isolated females. In males, octopamine levels were higher in isolated than in crowded last-instar hoppers; regardless of phase, the levels were low and similar in adult males on day 1 and day 5 after fledging and again higher in isolated than in crowded sexually mature males. Also, Benichou-Redouane and FuzeauBraesch [204] investigated octopamine content in several components of the nervous system in isolated and crowded adults of L. migratoria, 15-20 days after fledging and again reported higher octopamine content in isolated than in crowded locusts. On the other hand, Morton and Evans [205] studied octopamine distribution in isolated and crowded $S$. americana gregaria. They found neither phase-related nor sex-related differences in octopamine content of several components of the nervous system and of several muscles, as well as of whole heads.

Recently, Rogers et al. [206] studied phase-dependent differences and changes in neurotransmitters and neuromodulators, including octopamine, in last-instar hoppers and adults of S. gregaria. Detailed study by Rogers et al. [206] compared amounts of 13 different potential neurotransmitters and/or neuromodulators in the central nervous system (CNS) of final instar locust nymphs undergoing phase transition and between long-term solitarious and gregarious adults, $S$. gregaria. They found that, long-term gregarious and solitarious nymphs differs in 11 of the 13 substances analysed: eight increased in both the brain and thoracic nerve cord (including glutamate, GABA, dopamine and serotonin), whereas three decreased (acetylcholine, tyramine and citrulline). Adult locusts of both extreme phases were similarly different. Isolating larval gregarious locusts led to rapid changes in seven chemicals equal to or even exceeding the differences seen between long-term solitarious animals. Crowding larval solitarious locusts led to rapid changes in six chemicals towards gregarious values within the first $4 \mathrm{~h}$ (by which time gregarious behaviours are already being expressed), before returning to nearer long-term solitarious values $24 \mathrm{~h}$ later. Serotonin in the thoracic ganglia, however, did not follow this trend, but showed a nine-fold increase after a $4 \mathrm{~h}$ period of crowding. After crowding solitarious nymphs for a whole larval stadium, the amounts of all chemicals, except octopamine, were similar to those of long-term gregarious locusts.

Additionally, there are multiple indications that it is likely that octopamine plays an important role in the process of locust gregarization [207, 208]. Verlinden et al. [208] found two partial sequences of putative octopamine receptors in the desert locust, S. gregaria (sgOct $\alpha \mathrm{R}$ and $s g \mathrm{O} c t \beta \mathrm{R})$ and investigated their transcript levels in males and females of both phases and during the transition between long-term solitarious and gregarious locusts. The transcript levels of $s g$ Oct $\alpha \mathrm{R}$ are the highest in the central nervous system, whereas those of $s g \mathrm{Oct} \beta \mathrm{R}$ are the highest in the flight muscles, followed by the central nervous system. The two putative octopamine receptors found in S. gregaria, $s g \mathrm{O} c t \alpha \mathrm{R}$ and $s g \mathrm{Oct} \beta \mathrm{R}$, show higher transcript levels in long-term gregarious locusts compared to solitarious ones [208]. Moreover, the rise of $s g O c t \beta R$ transcript levels already appears during the first $4 \mathrm{~h}$ of gregarization, in which the behavioural changes take place.

In 2009 a major breakthrough was achieved in the understanding the role of neurotransmitters and neuromodulators in locust phase polyphenism. Anstey et al. [209] explored the role of serotonin in the mediation of behavioural gregarization in S. gregaria in a series of detailed pharmacological manipulations. They reported that, when solitarious locusts acquire full gregarious behavioural characteristics within the first 2 hours of forced crowding; this period coincides with a substantial but transient increase in the amount of serotonin [5-hydroxytryptamine (5-HT)] specifically in one region of the CNS, the thoracic ganglia, but not the brain. Moreover, they crowded solitarious locusts for 0,1 , or 2 hours to generate the entire gamut of behaviour, from solitarious to gregarious, and then analysed the degree of behavioural gregarization by using a binary logistic regression model. Anstey et al. [209] found that the amount of serotonin was significantly positively correlated with the extent of gregarious behaviour across this entire range. Locusts that behaved the most gregariously had approximately three times more serotonin than more solitariously behaving locusts. Furthermore, the amount of serotonin only corresponded with the degree of gregarization but not the duration of crowding, per se.

Behavioural gregarization can be acquired via two distinct sensory pathways; a thoracic pathway driven by mechanosensory stimulation of the hind legs as locusts jostle each other and a cephalic pathway in which the combined sight and smell of other locusts is the necessary stimulus [210-212]. Locusts stimulated via either sensory pathway displayed similar levels of gregarious behaviour after 2 hours [209]. Interestingly, Anstey et al. [209] found that both gregarizing stimuli lead to an increase in the amount of serotonin in the thoracic ganglia that correlated with the degree of behavioural gregarization. On the other hand, Anstey et al. [209] studied the effects of serotonin receptor agonists ( $\alpha$-methylserotonin and 5-carboxamidotryptamine) and antagonists (ketanserin and methiothepin) on behavioural gregarization of S. gregaria. They found that the locusts injected with the antagonists failed to gregarize in response to either stimulus regime, in contrast to saline-injected controls. Whereas, animals injected in the thoracic ganglia with a mixture of two serotonin agonists, showed a significant shift toward gregarious behaviour as compared with salineinjected controls. This pioneer study by Anstey et al. [209] showed for the first time that gregarizing stimuli cause serotonin to increase in the thoracic CNS and exogenous serotonin increases likelihood of locust behaving gregariously. Therefore, their data clearly indicate that elevation of seroto- 
nin in the thoracic ganglia is both necessary and sufficient for initiation of behavioural phase change.

\section{The Role of Peptides and Proteins}

In an analysis of the haemolymph protein pattern of $S$. gregaria using 2D-gel electrophoresis, three solitary-specific and 17 crowded-specific spots were recorded providing that a number of proteins are expressed and repressed in respect to the phase state [127]. Moreover, Rahman et al. [213] investigated differences in peptide pattern of the haemolymph of solitary and gregarious animals of S. gregaria. A $6 \mathrm{kDa}$ peptide was identified as a novel phase specific marker. This peptide was found to be quite abundance in the haemolymph of crowd-reared adults, whereas the peptide level decreased with successive generation of solitary reared animals. The peptide is also present in freshly laid eggs [214]. The concentration in eggs is higher in those from crowd-reared locusts. It is likely that the peptide is transferred from the female's haemolymph into the eggs because injection of the peptide into females before oviposition increases the amount of the 6-kDa peptide in the eggs. In another approach, Clynen et al. [215] searched for differences in the neuopeptide populations of the CC and haemolymph of $S$. gregaria using HPLC and mass spectrometry. They recorded differences between two phases in number and amount of peptides present.

In extracts of CC, differences in the relative amounts of neuroparsin A, ovary maturing parsin, adipokinetic hormone (AKH) and AKH-precursor-related peptide [216, 217] were found. However, direct effects of these peptides or the reported differences in their amounts, on phase characteristics have not yet been demonstrated.

\section{The Role of the Central Nervous System (CNS)}

Locusts are a physogenetically heterogeneous insect group within the family Acrididae, typically demonstrating a pronounced ability to change phases from the solitary to gregarious in response to population density [2, 70]. Phenotypic phase changes of locust species are linked with differences in many traits such as morphology, behaviour, colouration, endocrine balance, disease resistance, developmental and reproductive physiology [for review see 7]. The existence of these two extremely different forms or phases, also designated as phase polyphensim, is a fascinating example of phenotypic plasticity, whereby two obviously different phenotypes are encoded by the same genome [2, 70]. Conversion between the two phases is termed phase transition, which is a reversible, continuous process that is accompanied by the occurrence of several intermediate forms $[2,70]$.

The CNS plays a crucial role in these early gregarizing effects. Sensory stimuli generated by the presence of other locusts can induce changes in the titres of several neurotransmitters (see Section 5). The involvement of the CNS is not surprising since it constitutes the primary systemic control center that is integrating sensory input, generates behavioural responses and regulates many physiological processes. In addition, although crowded-reared locusts are on average smaller, their brain was found to be $30 \%$ larger than that of isolated-reared animals and to be differently proportionate [218]. Elevated population density leads to increased compe- tition for food and forces the locusts to alter their foraging strategy. Since foraging behaviour and social life style have already been associated with differences in the brain volume of insects [219-224], these may also be involved in distinguishing gregarious from solitarious brain size [218]. Furthermore, serotonin has been demonstrated to be a crucial central mediator of the behavioural phase transformation [209]. During the first hours of forced crowding a temporary increase in serotonin has been observed in thoracic ganglia [206]. However, development towards the gregarious phase is not only characterized by a behavioural shift. In later stages of gregarization (which can comprise several generations) multiple physiological processes are affected. These include reproduction, development and determination of life span [7, 225]. However, to a great extent, the molecular basis underlying all these phenotypic changes still remains elusive.

Moreover, Franz et al. [226] used differential display PCR to study brain area-specific gene expression of gregarious $S$. gregaria without making a comparison with solitary animals. They identified 7 area specific differentially expressed amplicons: 3 from optic lobes, 3 from the thoracic ganglia and one from the midbrain. Differential display transcriptase polymerase chain reaction (DDRT-PCR) in combination with semi-quantitative RT-PCR was used to compare differences in gene expression between the solitary and gregarious phase of S. gregaria [227]. The authors were able to partially identify a gene which is dominantly expressed in brains of the solitary phase and one which is dominantly expressed in brains of gregarious animals. The gregarious specific gene fragment shows homology to the SPARC (Secreted protein, acidic, rich in cysteine) gene. The expression level for the solitary phase specific gene was 2 times higher in solitary animals as compared to gregarious ones, while the gregarious gene gave a 4-fold higher expression level in gregarious animals than in solitaries.

More recently, Badisco et al. [228] have generated 34,672 raw expressed sequence tags (EST) from the CNS of desert locusts in both phases, and developed an S. gregaria EST database. They demonstrated that construction of this database did not result in a high degree of redundancy of locust transcriptomic data. Analysis of the database by Badisco et al. [228] already allowed us to functionally annotate 3,887 sequences, many of which are annotated as involved in neuronal signaling and signal transduction. Moreover, they identified several genes displaying significantly differential transcript levels in isolated- and crowded-reared desert locusts. Interestingly, some of these are predicted to be involved in development and modeling of the nervous system. These observations contribute to the view that density-dependent behavioural plasticity in locust is not only defined by innate signaling pathways, but represents a more sophisticated adaptation for coping with complex differences in environmental situations, including neural plasticity. By specifically focusing on the CNS, this $S$. gregaria EST database will most certainly contribute to further studies unraveling the complex regulation of phase transition and allow studying neuro-endocrine control mechanisms of certain physiological processes. Furthermore, parallel studies focusing on phase polyphenism and factors involved in nervous system development will most probably lead to novel insight in phenomena of neuroplasticity in general. 


\section{CONCLUDING REMARKS}

Locust phase polyphenism is continuous and a series of intermediates (transients) exists between the two extreme phases. Population density is the primary factor governing desert locust phase polyphenism. Under natural conditions, or in the laboratory, crowding induces characteristics of the gregarious phase, whereas isolation promotes those of the solitarious phase. However, phase transformation is a complex phenomenon; some phase characteristics change within hours, but some others show changes in generation.

Locust density is the primary extrinsic factor that affects phase transformation and pheromone production. Available information in $\mathrm{JH}$, ecdysteroids, [His ${ }^{7}$-corazonin and serotonin suggests that these hormones are intrinsic factors influencing desert locust phase polyphenism, but this possibility requires more and direct experimental testing. On the other hand, one of the main questions in locust physiology is still how changes in environmental factors and population density influence the nervous and endocrine systems allowing the choice of the solitary-gregarious pathway.

Now a day, some of the key pheromones of the gregarious phase have been characterized. Chemical communication is also shown to be important in the life style of the solitarious phase. Recent studies have explored possible roles of some hormones in the regulation of pheromone emission. Nonetheless, the exact roles of these hormones in pheromone production are not yet resolved and remain to be elucidated.

The breakthroughs of the past 15 years in our understanding of how different hormones may interact to control desert locust phase polyphenism are exciting and should stimulate redoubling of efforts to elucidate how all these factors interact. In addition, the study of the molecular genetics of locust phase change was greatly advanced by development of an EST-based microarray for S. gregaria. Identification of such genes is likely to increase our understanding of the molecular events underlying phase transition.

In conclusion, during the past decade, considerable progress has been made in identifying the endocrine mechanisms that regulate desert locust phase polyphenism. However, because of the complexity of this problem, only the broad outlines of potential regulatory mechanisms can be seen at present. Moreover, despite important advances presented in this review, the endocrine mechanisms that regulate desert locust phase polyphenism are clearly more complex, and much remains to be done on the desert locust.

Despite important advances discussed above, the endocrine mechanisms that regulate phase polyphenism as a whole remain largely an open issue. Future studies on the endocrine regulation of desert locust phase polyphenism should focus on four areas. First, basic studies on the roles of $\mathrm{JH}$ and ecdysteroids in regulation of phase polyphenism are still important given that direct measures of hormone titres at phase transition. Second, no published information is available on phase-specific differences in any hormone receptor. Third, detailed investigations are needed on the roles of hormone interaction in the regulation of desert locust phase polyphenism. Finally, detailed investigations of the mecha- nisms by which hormones differentially regulate desert locust phase polyphenism.

\section{ACKNOWLEDGEMENTS}

Comments and suggestions of two anonymous reviewers are greatly appreciated. I am thankful to my wife, Amal Zakaria for continuous encouragement, valuable suggestions, discussion and reading the manuscript. I also thank Professor David L. Denlinger (Department of Entomology, The Ohio State University, USA) for encouragement and critical reading the manuscript.

\section{CONFLICT OF INTEREST}

None declared.

\section{REFERENCES}

[1] Uvarov BP. A revision of the genus Locusta with a new theory as to periodicity and migration of locusts. Bull Entomol Res 1921; 12: 135-63.

[2] Uvarov BP. Grasshoppers and locusts. Cambridge, UK: Cambridge University Press 1966;p.1.

[3] Simpson SJ, Sowrd GA, Nathan L. Polyphenism in insects.Curr Biol 2011; 21: 738-49.

[4] Pener MP. Locust phase polymorphism and its endocrine relations. Adv Insect Physiol 1991; 23: 1-79.

[5] Pener MP, Yerushalmi Y. The physiology of locust phase polymorphism: an update. J Insect Physiol 1998; 44: 365-77.

[6] Tawfik AI, Sehnal F. A role for ecdysteroids in the phase polymorphism of the desert Locust. Physiol Entomol 2003; 28: 19-24.

[7] Pener MP, Simpson SJ. Locust phase polyphenism: an update. Adv Insect Physiol 2009; 36: 1-286.

[8] Skaf R. The development of a new plague of the desert locust Schistocerca gregaria (Forskal) (Orthoptera: Acrididae) 19851989. Boletin de Sanidad Vegetal Fuera de Serie 1990; 20: 59-66.

[9] Skaf R, Popov GB, Roffey J. The desert locust: an international challenge. Philos Trans R Soc Lond 1990; 328(B): 525-38.

[10] Showler AT, Potter CS. Synopsis of the 1986-1989 desert locust (Othoptera: Acrididae) plague and the concept of strategic control. Am Entomol 1991; 37: 106-10.

[11] Bell M. The 2004 desert locust outbreak. Bull Am Meteor Soc 2005; 86: S60 special section on 'State of the climate in 2004.

[12] Ceccato P, Cressman K, Giannini A, Trzaka S. The desert locust upsurge in West Africa (2003-2005): Information on the desert locust early warning system and the prospects for seasonal climate forecasting. Int J Pest Manag 2007; 53: 7-13.

[13] Dirsh VM. A new biometrical phase character in locusts. Nature 1951; 167: 281-2.

[14] Dirsh VM. Morphometrical studies on phases of the desert locust. Anti-Locust Bull 1953; 16: 1-34.

[15] Gunn DL, Hunter-Jones P. Laboratory experiments on phase differences in locusts. Anti-Locust Bull 1952; 12: 1-29.

[16] Hunter-Jones P. Laboratory studies on the inheritance of phase characters in locusts. Anti-Locust Bull 1958; 29: 1-35.

[17] Stower WJ, Davies DE, Jones IB. Morphometric studies of the desert locust, Schistocerca gregaria. J Anim Ecol 1960; 29: 30939.

[18] Symmons PM. A morphometric measure of phase in the desert locust, Schistocerca gregaria (Forsk.). Bull Entomol Res 1968; 58: 803-9.

[19] Nickerson B. Pigmentation of hoppers of the desert locust (Schistocerca gregaria Forskal) in relation to phase coloration. Anti-Locust Bull 1956; 24: 1-34.

[20] Ellis PE, Carlisle DB. The prothoracic gland and colour change in locusts. Nature 1961; 190: 268-9.

[21] Ellis PE. Learning and social aggregation in locust hoppers. Anim Behav 1959; 7: 91-106.

[22] Ellis PE, Pearce A. Innate and learned behavior patterns that lead to group formation in locust hoppers. Anim Behav 1962; 10: 305-18. 
[23] Gillett SD. Social aggregation of adult Schistocerca gregaria and Locusta migratoria migratorioides in relation to the final moult and aging. Anim Behav 1972; 20: 526-33.

[24] Gillett SD. Social determinants of aggregation behavior in adults of the desert locust. Anim Behav 1973; 21: 599-606.

[25] Gillett SD. Solitarization in the desert locust, Schistocerca gregaria (Forskal) (Orthoptera: Acrididae). Bull Entomol Res 1988; 78: 623-31.

[26] Roessingh P, Simpson SJ, James S. Analysis of phase-related changes in behviour of desert locust nymphs. Proc R Soc Lond 1993; 252: 43-9.

[27] Roessingh P, Simpson SJ. The time-course of behavioural phase change in nymphs of the desert locust, Schistocerca gregaria. Physiol Entomol 1994;19: 191-7.

[28] Islam MS, Roessingh P, Simpson SJ. Parental effects on the behavior and colouration of nymphs of the desert locust Schistocerca gregaria. J Insect Physiol 1994; 40: 173-81.

[29] Injeyan HS, Tobe SS. Phase polymorphism in Schistocerca gregaria: Reproductive parameters. J Insect Physiol 1981; 27: 97102.

[30] Ocheing-Odero JPR, Ndugo SM, El Bashir S, Capstick PB. A method for rearing crowded (gregarious) and isolated (solitary) locusts (Orthoptera: Acrididae) in the laboratory. In: Njagi PGN, Chaudhury MFP, Eds. Proceedings of workshop on effective networking of research and development on environmentally sustainable Locust Control Methods among Locust affected Countries. Nairobi, Kenya: ICIPE Science Press 1994; pp. 33-44.

[31] Thomas JG. The sense organs on the mouthparts of the desert locust (Schistocerca gregaria). J Zool 1966; 148: 420-48.

[32] Chapman RF. Chemoreception: The significance of receptor numbers. Adv Insect Physiol 1982; 16: 247-368.

[33] Blaney WM, Simmonds MSJ. The chemoreceptors. In: Chapman RF, Joern A, Eds. Biology of grasshoppers. New York: John Wiley and Sons 1990; pp. 1-37.

[34] Ochieng SA, Hallberg E, Hansson BS. Fine structure and distribution of antennal sensilla of the desert locust, Schistocerca gregaria. Cell Tissue Res 1998; 291: 525-36.

[35] Tawfik AI, Awad AA. Effect of shifting to crowded or solitary conditions on the antennal sensilla of the desert locust, Schistocerca gregaria. J Union Arab Biol 2001; 15(A): 147-70.

[36] Mordue AJ. Some effects of amputation of the antennae on pigmentation, growth and development in the locust, Schistocerca gregaria. Physiol Entomol 1977; 2: 293-300.

[37] Loher W. The chemical acceleration of the maturation process and its hormonal control in the male of the desert locust. Proc R Soc Lond B 1961; 153(B): 380-97.

[38] Loher W. Contributions to the study of sexual behavior of Schistocerca gregaria Forskal (Orthoptera: Acrididae). Proc R Entomol Soc Lond 1959; 34(A): 49-56.

[39] Saini RK, Rai MM, Hassanali A, Wawiye J. Odongo H. Semiochemicals from froth of egg pods attract ovipositing female Schistocerca gregaria. J Insect Physiol 1995; 41: 711-6.

[40] Heifetz Y, Applebaum SW. Density-dependent physiological phase in a non migratory grasshoppers, Aiolopus thalassinus. Entomol Exp Appl 1995;77: 251-62.

[41] Chapman RF, Lee JC. Environmentals effects on numbers of peripheral chemoreceptors on the antennae of a grasshopper. Chem Senses 1991; 16: 607-16.

[42] Hansson BS, Ochieng SA, Grosmaitre X, Anton S, Njagi PGN. Physiological responses and central nervous projections of antennal olfactory neurons in the adult desert locust, Schistocerca gregaria (Orthoptera: Acrididae). J Comp Physiol A 1996; 179(A): 157-67.

[43] Ochieng SA, Hansson BS. Responses of olfactory receptor neurons to behaviourally important odours in gregarious and solitarious desert locust, Schistocerca gregaria. Physiol Entomol 1999; 24: 2836.

[44] Greenwood M, Chapman RF. Differences in numbers of sensilla on the antennae of solitarious and gregarious Locusta migratoria L. (Orthoptera: Acrididae). Int J Insect Morphol Embryol 1984; 13: 295-301.

[45] Rogers SM, Simpson SJ. Experience-dependent changes in the number of chemosensory sensilla on the mouthparts and antennae of Locusta migratoria. J Exp Biol 1997; 200: 2313-21.

[46] Bernays EA, Chapman RF. Phentotypic plasticity in numbers of antennal chemoreceptors in grasshoppers: Effect of food. J Comp Physiol 1998; 183: 69-76.
[47] Technau GM. Fiber number in the mushroom bodies of adult, Drosophila melanogaster depends on age, sex, and experience. J Neurogenet 1984; 1: 113-26.

[48] Roselli-Austin L, Williams J. Enriched neonatal odor exposure leads to increased numbers of olfactory bulb and granule cells. Dev Brain Res 1990; 51: 135-7.

[49] Hassanali A, Njagi PGN, Bashir MO. Chemical ecology of locusts and related acridids. Annu Rev Entomol 2005; 50: 223-45.

[50] Schafer R, Sanchez TV. The nature and development of sex attractant specificity in cockroaches of the genus Periplaneta. I. Sexual dimorphism in the distribution of antennal sense organs in five species. J Morphol 1976; 149: 139-58.

[51] Heifetz Y, Voet H, Applebaum SW. Factors affecting behavioural phase transition in the desert locust, Schistocerca gregaria. J Chem Ecol 1996; 22: 1717-34.

[52] Stower WJ. The colour patterns of hoppers of the desert locust (Schistocerca gregaria forskal). Anti-Locust Bull 1959; 32: 1-75.

[53] Staal GB. Studies on the physiology of phase induction in Locusta migratoria migratorioides R \& F. Wageningen, The Netherlands: H Veenman \& Zonen NV 1961 (also as Meded Landbouwhogecsh Wageningen No:72 and Publ Fds Landb Exp Bur 1916-18; 40: 1125).

[54] Schafer R. The nature and development of sex attractant specificity in cockroaches of the genus Periplaneta. III. Normal intra- and inter- specific behavioral responses and responses on insects treated with juvenile hormone. J Exp Zool 1977; 199: 73-84.

[55] Schafer R. The nature and development of sex attractant specificity in cockroaches of the genus Periplaneta. IV. Electrophysiological study of attractant specificity and its determination by JH. J Exp Zool 1977; 199: 189-208.

[56] Ramaswamy SB, Gupta AP. Effects of juvenile hormone on sense organs involved in mating behavior of Blattela germanica (L.) (Dictyoptera: Blattella). J Insect Physiol 1981; 27: 601-8.

[57] Blaney WM, Chapman RF, Cook A. The structure of the terminal sensilla on the maxillary palps of Locusta migratoria (L.) and changes associated with moulting. Z Zelforsch Mikrosk Anrt 1971; 121: 48-68.

[58] Gantzy W. Development of the filiform hairs on the cerci of Gryllus bimaculatus Deg. (Saltatoria, Gryllidae). Cell Tissue Res 1978; 187: 1-24.

[59] Ameismeier F. Embryonic development and molting of the antennal coeloconic no pore- and doubled-walled wall sensilla in $\mathrm{Lo}$ custa migratoria (Insecta, Orthoperoidea). Zoomorphology 1985; 105: 356-66.

[60] Seidl S. Structure and differentiation of the sensilla of the ventral sensory field on the maxillary palp of Periplaneta americana (Insecta, Blattodae), paying special attention to the celiogenesis of the sensory cells. Zoomorphology 1991; 111: 35-47.

[61] Lienhard MC, Stocker RF. The development of the sensory neuron pattern in the antennal disc of wild type and mutant (Lz3, ss-a) Drosophila melanogaster. Development 1991; 112: 1063-76.

[62] Ray K, Hartenstein V, Rodrigues V. Development of the taste bristles on the labellum of Drosophila melanogaster. Development Biol 1993; 155: 26-37.

[63] Torto B, Njagi PGN, Hassanali A, Amiani H. Aggregation pheromone system of nymphal gregarious desert locust, Schistocerca gregaria (Forskal). J Chem Ecol 1996; 22: 2273-81.

[64] Obeng-Ofori D, Torto B, Hassanali A. Evidence for mediation of two releaser pheromones in aggregation behavior of the gregarious desert locust, Schistocerca gregaria. J Chem Ecol 1993; 19: 166576.

[65] Obeng-Ofori D, Njagi PGN, Torto B, Hassanali A, Amiani H. Sex differentiation studies relating to releaser aggregation pheromones of the desert locust, Schistocerca gregaria. Entomol Exp Appl 1994; 73: 85-91.

[66] Obeng-Ofori D, Torto B, Njagi PGN, Hassanali A, Amiani H. Fecal volatiles as part of the aggregation pheromone complex of the desert locust, Schistocerca gregaria (Forskal) (Orthoptera: Acrididae). J Chem Ecol 1994; 20: 2077-87.

[67] Torto B, Obeng-Ofori D, Njagi PGN, Hassanali A, Amiani H. Aggregation pheromone system of adult gregarious desert locust, Schistocerca gregaria (Forskal). J Chem Ecol 1994; 20: 1749-62.

[68] Deng AL, Torto B, Hassanali A, Ali EE. Effects of shifting to crowded or solitary conditions on pheromone release and morphometrics of the desert locust, Schistocerca gregaria (Forsk.) J Insect Physiol 1996; 42: 771-6. 
[69] Seidelmann K, Luber K, Ferenz HJ. Analysis of release and role of benzylcyanide in male desert locusts, Schistocerca gregaria. J Chem Ecol 2000; 26: 1897-910.

[70] Uvarov BP. Grasshoppers and locusts. London, UK, Centre for Overseas Pest Research 1977; p.2.

[71] Dillon RJ, Vennard CT, Charnley AK. Exploitation of gut bacteria in the locust. Nature 2000; 403: 851.

[72] Seidelmann K, Luber K, Ferenz HJ. Wings and legs are production sites for the desert locust courtship-inhibition pheromone, phenylacetonitrile. J Insect Physiol 2003; 49: 1125-33.

[73] Anton, S, Hansson BS. Antennal lobe interneurons in the desert locust, Schistocerca gregaria (Forskal): processing of aggregation pheromones in adult males and females. J Comp Neurol 1996; 370: 85-96.

[74] Seidelmann K, Ferenz HJ. Courtship inhibition pheromone in desert locusts, Schistocerca gregaria. J Insect Physiol 2002; 48: 9916.

[75] Ferenz HJ, Seidelmann K. Pheromones in relation to aggregation and reproduction in desert locusts. Physiol Entomol 2003; 28: 11-8.

[76] Seidelmann K,Warnstorff K, Ferenz HJ. Phenylacetronitrile is a male specific repllent in gregarious desert locusts, Schistocerca gregaria. Chemoecology 2005; 15: 37-43.

[77] Rono E, Njagi PGN, Bashir MO, Hassanali A. Concentration dependent parsimonious releaser roles of gregarious male pheromone of the desert locust, Schistocerca gregaria. J Insect Physiol 2008; 54: 162-8.

[78] Mahamat H, Hassanali A, Odongo H, Torto B, El Bashir ES. Studies on the maturation-accelerating pheromone of the desert locust, Schistocerca gregaria (Orthoptera: Acrididae). Chemoecology 1993; 4: 159-64.

[79] Schmidt GH, Albutz R. Sexual maturation and yellow coloration of adult males in the gregarious desert locust, Schistocerca gregaria, in relation to volatile emitted (Caelifera: Acrididae). Entomol Generalis 2002; 26: 121-41.

[80] Mahamat H, Hassanali A, Ferenz H-J. Vitellogenin titres in normal and accelerated maturation of gregarious phase Schistocerca gregaria. Comp Biochem Physiol 1997; 226(B): 447-51.

[81] Mahamat H, Hassanali A, Odongo H. The role of different components of the pheromone emission of mature males of the desert locust, Schistocerca gregaria (Forskal) (Orthoptera: Acrididae) in accelerating maturation of immature adults. Insect Sci Appl 2000; 20: 1-5.

[82] Assad YOH, Hassanali A, Torto B, Mahamat H, Bashir NHH, El Bashir S. Effects of fifth-instar volatiles on sexual maturation of adult desert locust, Schistocerca gregaria. J Chem Ecol 1997; 23: 1373-88.

[83] Norris MJ. Aggregation response in ovipositing females of the desert locust, with special reference to the chemical factor. J Insect Physiol 1970; 16: 1493-515.

[84] Luga J, Hatte M. Properietes gregarisantes acquises par le sable dans lequel ont pondu a de nombreuses reprises des females gregaires de Locusta migratoria migratorioides $\mathrm{R}$. and $\mathrm{F}$. (orthoptere Acrididae). Acrida 1977; 6: 307-11.

[85] Luga J, Hatte M. L'activite gregarisante du sable de ponte chez Locusta migratoria L.: Action sur le comportement et la reproduction des individus. Ann Sci Nat Zool Biol Anim 1978; 20: 37-52.

[86] Rai MM, Hassanali A, Saini RK, Odongo H, Kahoro H. Identification of components of oviposition aggregation pheromone of the gregarious desert locust, Schistocerca gregaria (Forskal). J Insect Physiol 1997; 43: 83-7.

[87] Torto B, Assad YOH, Njagi PGN, Hassanali A. Evidence for additional pheromonal components mediating oviposition aggregation in Schistocerca gregaria. J Chem Ecol 1999; 25: 835-45.

[88] Highnam KC, Haskeil PT. The endocrine systems of isolated and crowded Locusta and Schistocerca in relation to oocyte growth, and the effects of flying upon maturation. J Insect Physiol 1964; 10: 849-64.

[89] Dale JF, Tobe SS. Biosynthesis and titre of juvenile hormone during the first gonotrophic cycle in isolated and crowded Locusta migratoria females. J Insect Physiol 1986; 32: 763-9.

[90] Tawfik AI. Ultrastructure of the corpus allatum in the solitary and gregarious adult female, Schistocerca gregaria in relation to CA volumetric changes and oocyte growth. Bull Fac Sci Assiut Univ 2000; 29(E): 17-32.

[91] Tawfik AI, Lackner B, Hassanali A, Osir E. Time-course haemolymph juvenile hormone titres in solitarious and gregarious adults of Schistocerca gregaria, and their relation to pheromone emission, CA volumetric changes and oocyte growth. J Insect Physiol 2000; 46: 1143-50.

[92] Joly P, Joly L. Resultats de greffes de corpora allata chez Locusta migratoria L. Ann Sci Nat (Zool) 11 Serie 1954; 15: 331-45.

[93] Joly P. Role joue pars les corpora allata dans la realization du polymorphism de phase chez Locusta migratoria L. In: Physiologie, compotement et Ecologie des Acridiens en Rapport avec la Phase, paris, 1962, Colloq Internat Centr National Rech Sci 1962; 114: 7788.

[94] Pener MP, Lazarovici P. Effect of exogenous juvenile hormone on mating behaviour and yellow colour in allatectomized adult male desert locusts. Physiol Entomol 1979; 4: 251-61.

[95] Odhiambo TR. Growth and the hormonal control of sexual maturation in the male desert locust, Schistocerca gregaria (Forskal). Trans R Entomol Soc Lond 1966; 118: 393-412.

[96] Tawfik AI, Mohammed M. Ultrastructure of the corpus allatum in the solitary and gregarious adult male, Schistocerca gregaria in relation to pheromone production. Bull Fac Sci Assiut Univ 1997; 1(E): 1-18.

[97] Norris MJ. Reproduction in the desert locust, Schistocerca gregaria (Forsk.) in relation to density and phase. Anti-Locust Bull 1952; 13: 1-49.

[98] Papillon M. Facteurs ecologiques et phases chez le criquet perlein, Schistocerca gregaria (Forsk.) II- Influence de la densite des populations. Bull Biol 1968; 102: 271-307.

[99] Papillon M, Cassier P, Girardie J, Lafon-Cazal M. L' influence de la temperature d'elevage sur l;activite endocrine de Schistocerca gregaria. Arch Biol 1976; 87: 103-27.

[100] Injeyan HS, Tobe SS. Phase polymorphism in Schistocerca gregaria: assessment of juvenile hormone synthesis in relation to vitellogenesis. J Insect Physiol 1981; 27: 203-10.

[101] Joly L, Joly P. Comparaison de la phase gregaire et de la phase solitaire de Locusta migratoria migratorioides (Orthoptere) du poin de vue de la teneur de leur hemolymphe en hormone juvenile. $\mathrm{C} \mathrm{R}$ Hebd Seanc Acad Sci Paris 1974; 279(D): 1007-9.

[102] Joly L, Hoffman J, Joly P. Control humoral de la differenciation phasaire chez Locusta migratoria migratorioides (R. \& F.) (Orthopteres). Acrida 1977; 6: 33-42.

[103] Fuzeau-Braesch S, Nicolas G, Baehr J-C, Porcheron P. A study of hormonal levels of the locust, Locusta migratoria cinerascens artificially changed to the solitary state by a chronic $\mathrm{CO}_{2}$ treatment of one minute per day. Comp Biochem Physiol 1982; 71(A): 53-8.

[104] Tawfik AI. Effect of isolation or crowding on morphometrics, hemolymph pigments and juvenile hormone titer of the desert locust, Schistocerca gregaria (Orthoptera: Acrididae). Bull Fac Sci Assiut Univ 2004; 33(E): 1-10.

[105] Joly P, Joly L, Halbwachs M. Controle humoral du development chez Locusta migratoria. Ann Sci Nat (Zool) 11 Serie 1956; 18: 257-61.

[106] Nemec V, Jarolim V, Hejno K, Sorm F. Natural and synthetic materials with insect hormone activity. 7. Juvenile activity of the farnesane-type compounds on Locusta migratoria L. and Schistocerca gregaria (Forsk.). Life Sci 1970; 9: 821-31.

[107] Roussel J-P. Action juvenilsante chromatotrope, gonadotrope, et cardiotrope de JH III sur Locusta migratoria. J Insect Physiol 1975; 21: 1007-15.

[108] Roussel J-P. Activite compare des hormones juveniles en C-18 (JHI) et en C-16 (JHIII) chez Locusta migratoria. J Insect Physiol 1976; 22: 83-8.

[109] Couillaud F, Mauchamp B, Girardie A. Biological, radiochemical and physiological evidence for the low activity of disconnected corpora allata in locust. J Insect Physiol 1987; 33: 223-8.

[110] Novak VJA, Ellis PE. The metamorphosis hormone and the phase dimorphism in Schistocerca gregaria. II- Implantations of the glands into hoppers reared in crowded conditions. Gen Comp Endocrinol 1967; 9: 477-8.

[111] Roussel J-P, Perron J-M. Action de substances mimetiques de l'hormone juvenile sur Schistocerca gregaria Forsk. Arch Zool Exp Gen 1974; 115: 251-62.

[112] Ellis PE, Novak VJA. Metamorphosis hormones and phase dimorphism in Schistocerca gregaria. I. Implantation of endocrine glands into hoppers reared in isolation; the effects on coloration. Endocr Exp 1971; 5: 13-8.

[113] Nicolas G. Recherché du role de l'hormone juvenile dans la realization de l'homochromie chez le croquet migrateur, Locusta 
migratoria L. Utilisation d'une hormone juvenile synthetique. C R Seanc Soc Biol 1971; 171: 503-7.

[114] Hasegawa E, Tanaka S. Genetic control of albinism and the role of juvenile hormone in pigmentation in Locusta migratoria (orthoptera: Acrididae). Jpn J Entomol 1994; 62: 315-24.

[115] Tanaka S. Hormonal control of body-color polymorphism in Locusta migratoria: interaction beteen [ $\left.\mathrm{His}^{7}\right]$-corazonin and juvenile hormone. J Insect Physiol 2000; 46: 1535-44.

[116] Pener MP, Ayali A, Ben-Ami E. Juvenile hormone is not a major factor in locust changes. In: Mauchamp B, Couillaud F, Baehr JC, Eds. Insect juvenile hormone research. Paris: Institut Nat Rec Agro 1992; pp.125-34.

[117] Pener MP. On the influence of corpora allata on maturation and sexual behaviour of Schistocerca gregaria. J Zool 1965; 147; 11936.

[118] Pener MP. Effects of allatectomy and sectioning of the nerves of the corpora allata on oocyte growth, male sexual behaviour, and colour change in adults of Schistocerca gregaria. J Insect Physiol 1967; 13: 665-84.

[119] Pener MP. Comparative studies on reciprocal interchange of the corpora allata between males and females of adult Schistocerca gregaria (Forskal) (Orthoptera: Acrididae). Proc R Entomol Soc Lond 1967; 42: 139-48.

[120] Amerasinghe EP. Effects of JH I and JH III on yellowing, sexual activity and pheromone production in allatectomized male Schistocerca gregaria. J Insect Physiol 1978; 24: 603-11.

[121] Pener MP. The differential effect of the corpora allata on yellow colouration in crowded and isolated Locusta migratoria migratotioides (R. \& F.) males. Acrida 1976; 5: 269-85.

[122] Wiesel G, Tappermann S, Dorn A. Effects of juvenile hormone and juvenile hormone analogues on the phase behaviour of Schistocerca gregaria and Locusta migratoria. J Insect Physiol 1996; 42: 385-95.

[123] Applebaum SW, Avisar E, Heifetz Y. Juvenile hormone and locust phase. Arch Insect Biochem Physiol 1997; 35: 375-91.

[124] Ignell R, Couillaud F, Anton S. Juvenile-hormone-mediated plasticity of aggregation behaviour and olfactory processing in adult desert locust. J Exp Biol 2001; 204: 249-59.

[125] Schneider M, Wiesel G, Dorn A. Effects of JH III and JH analogues on phase-related growth, egg maturation and lipid metabolism in Schistocerca gregaria females. J Insect Physiol 1995; 41: 23-31.

[126] Maeno K, Tanaka S. Artificial mainiaturization causes eggs laid by crowd-reared (gregarious) desert locust to produce green (solitarious) offspring in the desert locust, Schistocerca gregaria. J Insect Physiol 2009; 55: 849-54.

[127] Wedekind-Hirschberger S, Sickold S, Dorn A. Expression of phase-specific haemolymph polypeptides in a laboratory stain and field catches of Schistocerca gregaria. J Insect Physiol 1999; 45: 1097-103.

[128] Tawfik AI, Osir E, Hassanali A, Ismail S. Effects of juvenile hormone treatment on phase changes and pheromone production in the desert locust, Schistocerca gregaria. J Insect Physiol 1997; 43: 1177-82.

[129] Tawfik AI, Kellner R, Hoffmann K, Lorenz M. Purification, characterization and titre of haemolymph juvenile hormone binding proteins from Schistocerca gregaria and Gryllus bimaculatus. J Insect Physiol 2006; 52: 255-68.

[130] Tawfik AI, Abdel Salam SA, Awad AA. Characterization of the cytosolic protein from Schistocerca gregaria that bind juvenile hormone. J Egypt Ger Soc Zool 2004; 43(A): 399-419.

[131] Bergot BJ, Schooley DA, DeKort CAD. Identification of JH III as the principal juvenile hormone in Locusta migratoria. Experientia 1981; 37: 909-10.

[132] Temin G, Zander M, Roussel J-P. Physico-chemical (GC-MS) measurement of JH III titres during embryogenesis of Locusta migratoria. Invertebr Reprod Dev 1986; 9: 105-12.

[133] Hoffmann JA, Lagueux M, Hetru C, Charlet M, Goltzene F. Ecdysone in competent female adults and embryos of insects. In: Hoffmann JA, Ed. Progress in ecdysone research. North Holland, Amsterdam: Elsevier 1980; pp. 431-65.

[134] Hagedorn HH. The role of ecdysteroids in reproduction. In: Kerkut GA, Gilbert LI, Eds. Comprehensive insect physiology, biochemistry and pharmacology. Oxford: Pergoman Press 1985; Vol. 8: pp.205-62.
[135] Lagueux M, Hirn M, Hoffmann JA. Ecdysone during ovarian development in Locusta migratoria. J Insect Physiol 1977; 23: 10919.

[136] Glass H, Emmerich H, Spindler KD. Immunohistochemical localisation of ecdysteroids in the follicular epithelium of locust oocyte. Cell Tissues Res 1978; 194: 237-44.

[137] Goltzene F, Lagueux M, Charlet M, Hoffmann JA. The follicle cell epithelium of maturing ovaries of Locusta migratoria: a new biothynthesis tissue for ecdysone. Hoppe-Seyler's Z Physiol Chem 1978; 359: 1427-34.

[138] Gande AR, Morgan ED, Wilson ID. Ecdysteroid levels throughout the life cycle of the desert locust, Schistocerca gregaria. J Insect Physiol 1979; 25: 669-75.

[139] Dinan L, Rees H. The identification and titers of conjugated and free ecdysteroids in developing ovaries and newly-laid eggs of Schistocerca gregaria. J Insect Physiol 1981; 27: 51-8.

[140] Lagueux M, Harry P, Hoffmann JA. Ecdysteroids are bound to vitelline in newly laid eggs of Locusta. Mol Cell Endocrinol 1981; 24: 325-38.

[141] Scalia S, Morgan EM. A reinvestigation on the ecdysteroids during embryogenesis in the desert locust, Schistocerca gregaria. J Insect Physiol 1982; 28: 647-54.

[142] Sall C, Tsoupras G, Kappler C, et al. Fate of maternal conjugated ecdysteroids during embryonic development in Locusta migratoria. J Insect Physiol 1983; 29: 491-507.

[143] Tawfik AI, Vedrova A, Sehnal F. Ecdysteroids during ovarian development and embryogenesis in solitary and gregarious Schistocerca gregaria. Arch Insect Biochem Physiol 1999; 41: 134-43.

[144] Lagueux M, Hetru C, Goltzene F, Kappler C, Hoffmann JA. Ecdysone titre and metabolism in relation to cuticulogenesis in embryos of Locusta migratoria. J Insect Physiol 1979; 25: 709-23.

[145] Lagueux M, Hoffmann JA, Goltzene F, et al. Ecdysteroids in ovaries and embryos of Locusta migratoria. In: Hoffmann JH, Porchet M, Eds. Biosynthesis, metabolism and mode of action of invertebrate hormone. Berlin: Springer 1984; pp. 168-80.

[146] Hetru C, Lagueux M, Luu B, Hoffmann JA. Adult ovaries of Locusta migratoria contain sequence of biosynthetic intermediates for ecdysone. Life Sci 1978; 22: 2141-54.

[147] Gande AR, Morgan ED. Ecdysteroids in the developing eggs of the desert locust, Schistocerca gregaria. J Insect Physiol 1979; 25: 289-93.

[148] Scalia S, Sbrenna-Micciarelli A, Sbrenna G, Morgan ED. Ecdysteroid titers and location in developing eggs of Schistocerca gregaria. Insect Biochem 1987; 17: 227-36.

[149] Hagele BF, Wang F-H, Sehnal F, Simpson SJ. Effects of crowding, isolation, and transfer from isolation to crowding on total ecdysteroid content of eggs in Schistocerca gregaria. J Insect Physiol 2004; 50: 621-8.

[150] Sbrenna G. Roles of morphogenetic hormones in embryonic cuticle deposition in arthropods. In: Gupta AP, Ed. Morphogenetic hormones of arthropods: roles in histogenesis, organogenesis and morphogenesis. New Brunswick: Ruters University Press 1991; pp. 4480.

[151] Albrecht FO, Verdier M, Blackith RE. Maternal control of ovariole number in the progeny of the migratory locust. Nature 1959; 184 : 103-4.

[152] Papillon M. Etude preliminaire de la repercussion du groupement des Schistocerca gregaria (Forsk.). Bull Biol Fr Belg 1960; 93: 203-63.

[153] Morgan ED, Woodbridge AP, Ellis PE. Studies on the moulting hormones of the desert locust, Schistocerca gregaria. J Insect Physiol 1975; 21: 979-93.

[154] Morgan ED, Poole CF. The pattern of ecdysone levels during development in the desert locust Schistocerca gregaria. J Insect Physiol 1976; 22: 885-9.

[155] Baehr JC, Porcheron P, Papillon M, Davy F. Haemolymph levels of juvenile hormone, ecdysteroids and protein during the last two larval instars of Locusta migratoria. J Insect Physiol 1979; 25: 41521.

[156] Hirn M, Hetru C, Lagueux M, Hoffmann JA. Prothoracic gland activity and blood titers of ecdysone and ecdysterone during the last larval instar of Locusta migratoria. J Insect Physiol 1979; 25: 255-61. 
[157] Wilson ID, Morgan ED. Variation in ecdysteroid levels in $5^{\text {th }}$ instar larvae of Schistocerca gregaria in gregarious and solitary phases. J Insect Physiol 1978; 24: 751-6.

[158] Tawfik AI, Mat'hova A, Sehnal F, Ismail SH. Haemolymph ecdysteroids in the solitary and gregarious larvae of Schistocerca gregaria. Arch Insect Biochem Physiol 1996; 31: 427-38.

[159] El-Ibrashy MT, Abdel-Hamid M, Al-Refai A. Ecdysones and plant growth regulators induce solitarious characters and reduce fertility in the desert locust. Entomol Exp Appl 1976; 19: 214-20.

[160] Carlisle DB, Ellis PE. La persistance des glands ventrales cephaliques chez les Criquet solitaires. Comp Rend Heb Sean Acad Sci Par 1959; 249(D): 1059-60.

[161] Carlisle DB, Ellis PE. Prothoracic gland and gregarious behaviour in locusts. Nature 1963; 200: 603-4.

[162] Michel R. Etude experimentale de l'influence des glands prothoraciques sur l'activite de vol du Criquet pelerin Schistocerca gregaria. Gen Comp Endocrinol 1972; 19: 96-101.

[163] Tawfik AI, Vedrova A, Li W, Sehnal F, Obeng-Ofori D. Haemolymph ecdysteroids and the prothoracic glands in the solitary and gregarious adults of Schistocerca gregaria. J Insect Physiol 1997; 43: 485-93.

[164] Cassier P, Fain-Maurel MP. Influence de la photoperiode sur la persistance ou la degenerescence des glandes ventrales chez les imagos gregaires du Criquet migrateur. Etude experimentale et infrastructurale. Comp Rend Heb Sean Acad Sci Par 1968; 267(D): 646-8.

[165] Cassier P, Fain-Maurel MP. Etude infrastructural des glands de mue de Locusta migratoria (R et F.). III. Sur la persistance ou la degenerescence des glandes ventales chez les imagos solitaires. Arch Zool Exp Gener 1969; 110: 203-24.

[166] Hoffmann JA, Koolman J. Prothoracic glands in the regulation of ecdysone titres and metabolic fate of injected labelled ecdysone in Locusta migratoria. J Insect Physiol 1974; 20: 1593-601.

[167] Roussel J-P. La biosynthese de l'ecdysone par les glandes prothoraciques de Locusta migratoria incubees in vitro. Bull Soc Zool Fr 1992; 117: 37-43.

[168] Roussel J-P. Modification des tawx d'ecdysteroides selon la phase chez Locusta migratoria L. Bull Soc Zool Fr 1993; 118: 367-73.

[169] Charlet M, Roussel J-P, Rinternecht E, Berchtold J-P, Costet M-F. Developmental and morphogenetic alterations in larvae of Locusta migratoria reared on plant diet with a selectively modified sterol profile. J Insect Physiol 1988; 34: 787-96.

[170] Vandermissen T, De Loof A, Gu S-H. Both prothoracicotropic hormone and an autocrine factor are involved in control of prothoracic gland ecdysteroidogenesis in Locusta migratoria and Schistocerca gregaria. Peptides 2007; 28: 44-50.

[171] Tawfik AI. Sites of ecdysteroid biosynthesis in adult of the desert locust, Schistocerca gregaria. J Union Arab Biol 2004; 21: 73-90.

[172] Giraradie J, Girardie A. Lom OMP, a putative ecdysiotropic factor for the ovary in Locusta migratoria. J Insect Physiol 1996; 42: 21521.

[173] Gillott C, Ismail PM. In vito synthesis of ecdysteroid by the male accessory reproductive glands, testis and abdominal integument of the adult migratory grasshopper, Melanoplus sanguinipes. Invert Rep 1995; 27: 65-71.

[174] Dumser JB. The regulation of spermatogenesis in insects. Ann Rev Entomol 1980; 25: 341-69.

[175] Delbecque J-P, Weidner K, Hoffmann KH. Alternative sites for ecdysteroid production in insects. Invert Rep 1990; 18: 29-42.

[176] Tawfik AI. The effect of gregarisation or solitarisation on pheromone production and haemolymph ecdysteroids in adult, Schistocerca gregaria. J Egypt Ger Soc Zool 1997; 23(E): 77-91.

[177] Dillwith JW, Adams TS, Blomquist GJ. Correlation of housefly sex pheromone production with ovarian development. J Insect Physiol 1983; 29: 377-86.

[178] Blomquist GJ, Dillwith JW, Adams TS. Induction of female sex pheromone production in male houseflies by ovary implanted or 20-hydroxyecdysone. J Insect Physiol 1984; 30: 295-302.

[179] Adams TS, Dillwith JW, Blomquist GJ. The role of 20hydroxyecdysone in housefly sex pheromone biosynthesis. J Insect Physiol 1984; 30: 287-94.

[180] Girardie A, Cazal M. Role de la pars intercerebralis et des corpora cardiac sur la melanisation chez Locusta migratoria (L.). C R Hebd Seanc Acad Sci Par 1965; 261: 4525-7.

[181] Schoofs L, Baggerman G, Veelaert D, Breuer M, Tanaka S, De Loof A. The pigmentotropic hormone $\left[\mathrm{His}^{7}\right]$-corazonin, absent in
Locusta migratoria albino strain, occurs in an albino strain of Schistocerca gregaria. Mol Cell Endocrinol 2000; 168: 101-9.

[182] Baggerman G, Clynen E, Rahman MM, et al. Mass spectrometric evidence for the deficiency in the dark-color-inducing hormone, [His ${ }^{7}$-corazonin in an albino strain of Locusta migratoria as well as for its presence in solitary Schistocerca gregaria. Arch Insect Biochem Physiol 2001; 47: 150-60.

[183] Tanaka S. Hormonal deficiency causing albinism in Locusta migratoria. Zool Sci 1993; 10: 467-71.

[184] Tanaka S, Pener MP. A neuropeptide controlling the dark pigmentation in color polymorphism of the migratory locust, Locusta migratoria. J Insect Physiol 1994; 40: 997-1005.

[185] Yerushalmi Y, Livshits L, Pener MP. The dark-colour-inducing neurohormone of locusts in relation to an albino mutant Schistocerca gregaria. Physiol Entomol 2000; 25: 127-32.

[186] Tawfik AI, Tanaka S, De Loof A, et al. Identification of the gregarization-associated dark-pigmentotropin in locusts through an albino mutant. Proc Natl Acad Sci USA 1999; 96: 7083-7.

[187] Veenstra JA. Isolation and structure of corazonin, a cardioactive peptide from the American cockroach. FEBS Lett 1989; 250: 2314.

[188] Tanaka S. Induction of darkening by corazonins in several species of Orthoptera and their possible presence in ten insect orders. Appl Entomol Zool 2000; 35: 509-17.

[189] Hua Y-J, Ishibashi J, Saito H, et al. The identification of [ $\left.\mathrm{Arg}^{7}\right]$ corazonin in the silkworm, Bombyx mori and the cricket, Gryllus bimaculatus, as a factor inducing dark colour in an albino stain of the locust, Locusta migratoria. J Insect Physiol 2000; 46: 853-60.

[190] Veenstra JA. Presence of corazonin in three insect species, and isolation and identification of [ His $\left.^{7}\right]$-corazonin from Schistocerca americana. Peptides 1991; 12: 1285-9.

[191] Veenstra JA. Isolation and structure of Drosophila corazonin gene. Biochem Biophys Res Commun 1994; 204: 292-6.

[192] Hansen IA, Sehnal F, Meyer SR, Scheller K. Corazonin gene expression in the waxmoth, Galleria mellonella. Insect Mol Biol 2001; 10: 341-6.

[193] Predel R, Nachman RJ, Gade G. Myostimulatory neuropeptides in cockroaches: structures, distribution, pharmacological activities, and mimetic analogs. J Insect Physiol 2001; 47: 311-24.

[194] Tanaka Y, Hua Y-J, Roller L, Tanaka S. Corazonin reduces the spinning rate in the silkworm, Bombyx mori. J Insect Physiol 2002; 48: 707-14.

[195] Yerushalmi Y, Bhargava K, Gilon C, Pener MP. Structure-activeity relations of the dark-colour-inducing neurohormone of locusts. Insect Biochem Mol Biol 2002; 32: 909-17.

[196] Tanaka S. The role of [His $\left.{ }^{7}\right]$-corazonin in the control of body-color polymorphism in the migratory locust, Locusta migratoria (Orthoptera: Acrididae). J Insect Physiol 2000; 46: 1169-76.

[197] Hoste B, Simpson SJ, Tanaka S, Zhu D-H, De Loof A, Breuer M. Effects of $\left[\mathrm{His}^{7}\right]$-corazonin on the phase state of isolated-reared (solitarious) desert locusts, Schistocerca gregaria. J Insect Physiol 2002; 48: 981-90.

[198] Tanaka S. Endocrine mechanisms controlling body-color polymorphism in locusts. Arch Insect Biochem Physiol 2001; 47: 139-49.

[199] Maeno K, Tanaka S. Hormonal control of phase-reared changes in the number of antennal sensilla in the desert locust, Schistocerca gregaria: possible involvement of $\left[\mathrm{His}^{7}\right]$-corazonin. J Insect Physiol 2004; 50: 855-65.

[200] Tanaka S, Zhu D-H, Hoste B, Breuer M. The dark-color-inducing neuropeptide, [His ${ }^{7}$-corazonin, cause a shift in morphometric characteristics towards the gregarious phase in isolated-reared (solitarious) Locusta migratoria. J Insect Physiol 2002; 48: 106574.

[201] Yerushalmi Y, Tauber E, Pener MP. Phase polymorphism in Locusta migratoria: the relative effects of geographical strains and albinism on morphometrics. Physiol Entomol 2001; 26: 95-105.

[202] Fuzeau-Braesch S, David JC. Etude du taxu d'octopamine chez Locusta migratoria (Insecte: Orthoptere) comparison entre insects gregaires, solitaires et traite au gaz carbonique. C R Acad Sci Par 1978; 286(D): 697-9.

[203] Fuzeau-Braesch S, Coulon JF, David JC. Octopamine levels during the moult cycle and adult development in the locust, Locusta migratoria. Experientia 1979; 35: 1349-50.

[204] Benichou-Redouane K, Fuzeau-Braesch S. Comparaison des taux d'octopamine chez Locusta migratoria cinerascens gregaire, soli- 
taire et solitaries au gaz carbonique, dans different organs nerveux. C R Hebd Seanc Acad Sci Par 1982; 294: 385-8.

[205] Morton DB, Evans PD. Octopamine distribution in solitarious and gregarious forms of the locust, Schistocerca americana gregaria. Insect Biochem 1983; 13: 177-83.

[206] Rogers SM, Matheson T, Sasaki K, Kendrick K, Simpson SJ, Burrows $M$. Substantial changes in central nervous system neurotransmitters and neuromodulators accompany phase change in the locust. J Exp Biol 2004; 207: 3603-17.

[207] Verlinden H, Vleugels R, Marchal E, et al. The role of octopamine in locusts and other arthropods. J Insect Physiol 2010; 56: 854-67.

[208] Verlinden H, Vleugels R, Marchal E, et al. The cloning, phylogenetic relationship and distribution pattern of two new putative GPCR-type octopamine receptors in the desert locust (Schistocerca gregaria). J Insect Physiol 2010; 56: 868-75.

[209] Anstey ML, Rogers SM, Burrows M, Simpson SJ. Serotonin mediates behavioral gregarization underlying swarm formation in the desert locust. Science 2009; 323: 627-30.

[210] Roessingh P, Bouaichi A, Simpson SJ. Effects of sensory stimuli on the behavioural phase state of the desert locust, Schistocerca gregaria. J Insect Physiol 1998; 44: 883-93.

[211] Simpson SJ, McCaffery AR, Hagel BF, Dodgson T. Gregarious behavior in desert locust is evoked by touching their back legs. Proc Natl Acad Sci USA 2001; 98: 3895-7.

[212] Rogers SM, Matheson T, Despland E, Dodgson T, Burrows M, Simpson SJ. Mechanosensory-induced behavioural gregarization in the desert locust, Schistocerca gregaria. J Exp Biol 2003; 206: 3991-4002.

[213] Rahman MM, Vanden Bosch L, Baggerman G, et al. Search for peptidic molecular markers in hemolymph of crowd (gregarious) and isolated-reared (solitary) desert locusts, Schistocerca gregaria. Peptides 2002; 23: 1907-14.

[214] Rahman MM, Baggerman G, De Loof A, Breuer M. Purification, isolation and search for possible functions of a phase-related 6080Da peptidic from the haemolymph of the desert locusts, Schistocerca gregaria. Physiol Entomol 2003; 28: 39-45.

[215] Clynen E, Stubble D, De Loof A, Schoofs L. Peptide differential display: a novel approach for phase transition in locusts. Comp Biochem Physiol 2002; 132B: 107-15.

[216] Ayali A, Pener MP, Girardie J. Comparative study of neuropeptides from the solitary and gregarious Locusta. Arch Insect Biochem Physiol 1996; 31: 439-50.
[217] Ayali A, Pener MP, Sowa SM, Keeley LL. Adipokinetic hormone content of the corpora cardiac in gregarious and solitary migratory locusts. Physiol Entomol 1996; 21: 167-72.

[218] Ott SR, Rogers SM. Gregarious desert locust have substantially larger brains with altered proportions compared with the solitarious phase. Proc Biol Sci 2010; 277: 3087-96.

[219] Withers GS, Fahrbach SE, Robinson GE. Selective neuroanatomical plasticity and division of labour in the honeybee. Nature 1993; 364: 238-40.

[220] Durst C, Eichmuller S, Menzel R. Development and experience lead to increased volume of subcompartments of the honeybee mushroom body. Behav Neural Biol 1994; 62; 259-63.

[221] Gronenberg W, Heren S, Holldoble B. Age-dependent and taskrelated morphological changes in the brain and the mushroom bodies of the ant, Camponotus Floridanus. J Exp Biol 1996; 199: 2011-9.

[222] Riveros AJ, Gronenberg W. Brain allometry and neural plasticity in the bumblebee, Bombus acidentalis. Brain Behav Evol 2010; 75: 138-48.

[223] Molina Y, O'Donnell S. Mushroom body volume is related to social aggression and ovary development in the paperwasp, Polistes instabilis. Brain Behav Evol 2007; 70: 137-44.

[224] Molina Y, O'Donnell S. Age, sex and dominance-related mushroom body plasticity in the paperwasp, Mischocyttarus mastigophorus . Dev Neurobiol 2008; 68: 950-9.

[225] Verlinden H, Badisco I, Marchal E, Van Wielendaele P, Vanden Broeck J. Endocrinology of reproduction and phase transition in locusts. Gen Comp Endocrinol 2009; 162: 79-92.

[226] Franz O, Roder T, Gewecke M. Analysis of differential gene expression in the central nervous system of Schistocerca gregaria by differential display PCR. J Comp Physiol 1998; 182(A): 627-33.

[227] Rahman MM, Vandingenen A, Begum M, Breuer M, De Loof A, Huybrechts R. Search for phase specific genes in the brain of desert locusts, Schistocerca gregaria (orthoptera: Acrididae) by differential display polymerase chain reaction. Comp Biochem Physiol 2003; 135(A): 221-8.

[228] Badisco I, Huybrechts J, Simonet G, et al. Transcriptome analysis of the desert locust central nervous system: Production and annotation of a Schistocerca gregaria EST database. PLoS ONE 2011; 6: $1-22$.

This is an open access article licensed under the terms of the Creative Commons Attribution Non-Commercial License (http://creativecommons.org/ licenses/by-nc/3.0/), which permits unrestricted, non-commercial use, distribution and reproduction in any medium, provided the work is properly cited. 